2nd Department of Medicine and Cardiology Center, Medical Faculty, Albert Szent-Györgyi Clinical Center, University of Szeged

\title{
Advances in the assessment of cardiac amyloidosis
}

\author{
Dóra Melinda Földeák MD
}

\author{
PhD thesis
}

Tutor:

Prof. Attila Nemes MD, PhD, DSc

2018 


\section{Relevant publications}

\section{Full papers}

I. Földeák D, Nemes A, Kalapos A, Domsik P, Kormányos Á, Krenács L, Bagdi E, Borbényi Z. What should we know about cardiac amyloidosis? From clinical signs to treatment. Orv Hetil. 2017;158:1811-1818. (impact factor: 0.349)

II. Nemes A, Földeák D, Domsik P, Kalapos A, Kormányos Á, Borbényi Z, Forster T. Cardiac amyloidosisis associated with icreased aortic stiffness. J Clin Ultrasound. 2018;46:183-187. (impact factor: 0,906)

III. Nemes A, Földeák D, Domsik P, Kalapos A, Sepp R, Borbényi Z, Forster T. Different patterns of left ventricular rotational mechanics in cardiac amyloidosis - results from the three-dimensional speckle-tracking echocardiographic MAGYAR-Path study. Quant Imaging Med Surg. 2015;5:853-857.

IV. Földeák D, Kormányos Á, Domsik P, Kalapos A, Piros GÁ, Ambrus N, Ajtay Z, Sepp R, Borbényi Z, Forster T, Nemes A. Left atrial dysfunction in light-chain cardiac amyloidosis and hypertrophic cardiomyopathy. - A comparative three-dimensional speckle-tracking echocardiographic analysis from the MAGYAR-Path study. Rev Port Cardiol. 2017;36:905-913. (impact factor: 1.195)

V. Nemes A, Földeák D, Domsik P, Kalapos A, Kormányos Á, Borbényi Z, Forster T. Right atrial deformation analysis in cardiac amyloidosis - Results from the threedimensional speckle tracking echocardiographic MAGYAR-Path study. Arq Bras Cardiol (in press)(impact factor: 1.186)

VI. Nemes A, Földeák D, Kormányos Á, Domsik P, Kalapos A, Borbényi Z, Forster T. Cardiac amyloidosis associated with enlargement and functional impairment of the mitral annulus: Insights of the Three-Dimensional Speckle Tracking Echocardiographic MAGYAR-Path Study. J Heart Valve Dis. 2017;26:304-308. 


\section{Abstract}

I. Nemes A, Domsik P, Kalapos A, Sepp R, Foldeak D, Borbenyi Z, Forster T. Different patterns of left ventricular rotational mechanics in cardiac amyloidosis - a threedimensional speckle tracking echocardiographic study. Eur Heart J Cardiovasc Imaging 2014;15(Suppl.2):ii107.

II. Nemes A, Domsik P, Kalapos A, Sepp R, Földeák D, Borbényi Z, Forster T. Different patterns of left atrial dysfunction in cardiac amyloidosis and hypertrophic cardiomyopathy as assessed by three-dimensional speckle-tracking echocardiography. Eur Heart J Cardiovasc Imaging 2015;16(Suppl.2):ii225.

III. Nemes A, Foldeak D, Domsik P, Kalapos A, Borbenyi Z, Sepp R, Forster T. Mitral annular morphology and function in cardiac amyloidosis as assessed by threedimensional specke tracking echocardiography. Eur Heart J Cardiovasc Imaging 2016;17(Suppl.2):ii113.

IV. Nemes A, Foldeak D, Domsik P, Kalapos A, Kormanyos A, Borbenyi Z, Forster T. Aortic stiffness is increased in cardiac amyloidosis. Eur Heart J Cardiovasc Imaging 2017;18(Suppl.3):ii132-133.

V. Nemes A, Foldeak D, Domsik P, Kalapos A, Kormanyos A, Borbenyi Z, Forster T. Right atrial volumetric and strain analysis in light-chain (AL) cardiac amyloidosis - a three-dimensional speckle-tracking echocardiographic study. Eur Heart J Cardiovasc Imaging Imaging 2017;18(Suppl.3):ii185. 
Table of contents

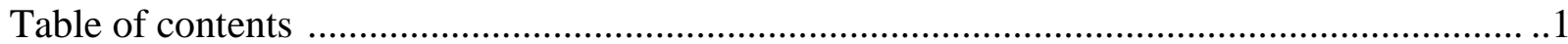

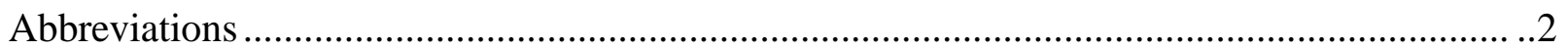

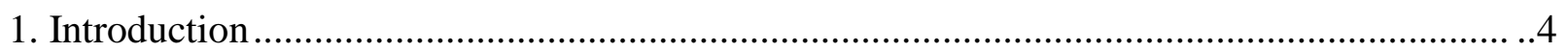





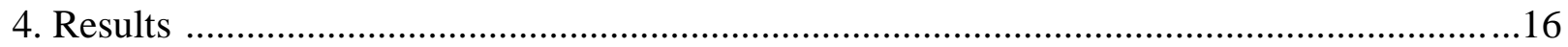

4.1. Echocardiographic ascending aortic elastic properties in cardiac amyloidosis....................16

4.2. Left ventricular rotational mechanics in biopsy-proven cardiac amyloidosis as assessed by three-dimensional speckle-tracking echocardiography................................................... 18

4.3 Comparing left atrial volumetric and functional characteristics between light-chain (AL) cardiac amyloidosis and hypertrophic cardiomyopathy by three-dimensional speckle-tracking echocardiography

4.4 Characterizing volumetric and functional properties of the right atrium in light chain (AL) cardiac amyloidosis by three-dimensional speckle-tracking echocardiography .....................26

4.5 Featuring the size and function of the mitral annulus in cardiac amyloidosis by three-

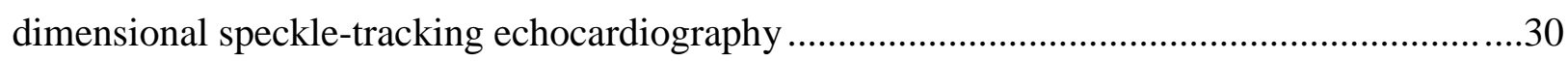

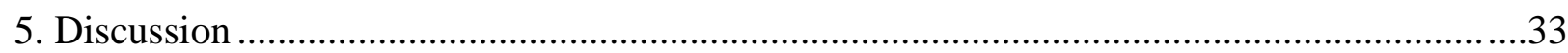

5.1. Echocardiographic ascending aortic elastic properties in cardiac amyloidosis.....................33

5.2. Left ventricular rotational mechanics in biopsy-proven cardiac amyloidosis as as sessed by three-dimensional speckle-tracking echocardiography.

5.3 Comparing left atrial volumetric and functional characteristics between light-chain (AL) cardiac amyloidosis and hypertrophic cardiomyopathy by three-dimensional speckle-tracking echocardiography .36

5.4 Characterizing the volumetric and functional properties of the right atrium in light chain (AL) cardiac amyloidosis by three-dimensional speckle-tracking echocardiography......

5.5 Featuring the size and function of the mitral annulus in cardiac amyloidosis by threedimensional speckle-tracking echocardiography

6. Conclusions (new observations)

7. References

8. Acknowledgements 48

Photocopies of essential publications 


\section{Abbreviations}

2D - two-dimensional

$3 \mathrm{D}$ - three-dimensional

3DS - three-dimensional strain

2DSTE - two-dimensional speckle-tracking echocardiography

3DSTE - three-dimensional speckle-tracking echocardiography

AP2CH - apical 2-chamber view

$\mathrm{AP} 4 \mathrm{CH}$ - apical 4-chamber view

AAEF - acive atrial emptying fraction

AASV - active stroke volume

$\mathrm{ACE}$ - angiotensin-converting enzyme

$\mathrm{AD}$ - aortic distensibility

AL - amyloid light-chain

AL-CA - light chain cardiac amyloidosis

AS - area strain

ASI - aortic stiffness index

$\mathrm{BP}$ - blood pressure

BMI - body mass index

$\mathrm{CS}$ - circumferential strain

DBP - diastolic blood pressure

DCM - dilated cardiomyopathy

DD - diastolic diameter

DM - diabetes mellitus

DS - systolic diameter

EDV - end-diastolic volume

$\mathrm{EF}$ - emptying fraction

ESV - end-systolic volume

HCM - hypertrophic cardiomyopathy

HCT - hematopoietic stem cell transplantation

IVS- interventricular septum

LA - left atrium

LV - left ventricle

$\mathrm{LVEF}_{2 \mathrm{D}}-$ left ventricle emptying fraction two-dimesional 
LV-RBR - left ventricle rigid body rotation

LS - longitudinal strain

MA - mitral annulus

MAA - mitral annulus area

MAD - mitral annulus diameter

MAFAC - mitral annulus fractional area change

MAFS - mitral annulus fractional shortening

MAFS $_{3 D}$ - mitral annulus fractional shortening three-dimensional

MAGYAR-Path Study - Motion Analysis of the heart and Great vessels bY three-dimensionAl speckle-tRacking echocardiography in Pathological cases Study

$\mathrm{MR}$ - mitral regurgitation

NCCM - noncompaction cardiomyopathy

NYHA - New York Heart Association

PAEF - passive atrial emptying fraction

PASV - passive atrial stroke volume

$\mathrm{PP}-$ pulse pressure

$\mathrm{RA}$ - right atrium

$\mathrm{RBR}$ - rigid body rotation

$\mathrm{RS}$ - radial strain

RT 3DSTE - real-time three-dimensional echocardiography

$\mathrm{RV}$ - right ventricle

SBP - systolic blood pressure

SD - systolic diameter

STE - speckle-tracking echocardiography

$\mathrm{SV}$ - stroke volume

T1DM- type 1 diabetes mellitus

TAEF - total atrial emptying fraction

TASV - total atrial stroke volume

TTR - transthyretin

$\mathrm{V}_{\max }-$ maximum atrial volume

$\mathrm{V}_{\min }-$ minimum atrial volume

$\mathrm{V}_{\text {preA }}$ - pre-atrial contraction volume 


\section{Introduction}

Systemic amyloidosis is a rare disease caused by the extracellular deposition of protein (amyloid) fibrils that are composed of low molecular weight subunits (5 to $25 \mathrm{kD}$ ) of various serum proteins (1). The amyloid fibrils progressively damage the structure and function of the affected tissue with variable clinical symptoms (2,3). For diagnosis of amyloidosis, biopsy from the affected organ or from (abdominal) subcutaneous adipose tissue is necessary in most cases (4). The pathological diagnosis is based on a special Congo red staining technique and the apple green bifringence which occurs under polarized light. The classification of amyloidosis depends on the type of the precursor protein including acquired monoclonal immunoglobulin light chain amyloidosis (AL), wild-type or hereditary transthyretin amyloidosis (TTR), acquired serum amyloid type (AA) and other rare types. The mortality is especially high in light chain (AL) amyloidosis $(5,6)$.

There are some warning signs that can draw attention to amyloidosis, such as nephrotic syndrome, tissue infiltration like macroglossia, respiratory disease, carpal tunnel syndrome, bleeding, cachexia, haematological disease as multiple myeloma and genetic predisposition. As for the clinical signs, syncope is a poor prognostic factor and occurs quite frequently in patients with cardiac involvement (7). Cardiac involvement in amyloidosis varies according to the type of the disease (1). The real incidence of cardiac amyloidosis is not known precisely and is often diagnosed only during autopsy (8). Heart failure usually occurs in cardiac amyloidosis due to the combination of decreased myocardial compliance and compressed myocardial cells. These changes develop due to the infiltration by amyloid deposits and could lead to restrictive cardiomyopathy (1).

AL amyloidosis is the most common type. In these cases, clonal plasmacell growth or other, B-cell dyscrasia can be found in the bone marrow. The AL amyloid fibrils are built of light chain fragments that can be kappa or lambda type. In lamda type, the cardiac involvement is more common. The presence of multiple myeloma is a bad prognostic factor. In $50 \%$ of the cases, the heart is affected in AL amyloidosis (9).

Regarding the diagnostic tools, biomarker examinations can be helpful. Two main biomarkers are used in amyloidosis, NT-proBNP and cTnT and they are in strong correlation with the prognosis and the therapeutic effect (10). Generally, the Mayo revised prognostic staging system might be used in cardiac amyloidosis. It includes not only the biomarkers, but also the circulating light chain level (11). The NT-proBNP level is the indicator of survival also in newly diagnosed patients, but also in those receiving systemic treatment (12). However, in 
renal impairment it should be evaluated watchfully, as the level can be elevated without clinical signifance (13).

As for the mechanical procedures, electrocardiography can show some warning signs, such as low voltage, in chest reduction $\mathrm{R}$ wave progression is decreased and sometimes conduction abnormalities can occur, like first degree atrioventicular block, non-specific intraventricular conduction abnormalities, second or third degree atrioventucular block, atrial fibrillation or flatter or rarely ventricular arritmias (14). Nowdays, all patients suffering from cardiac complaints undergo echocardiography. If the possibility of amyloidosis is present, echocardiography must be performed. Sometimes, only in advanced stage, specific discrepancies can be seen. The key of the diagnosis is the biatrial dilatation and the biventricular, valvular and septal thickening of the walls (15). Diastolic impairment can be an early sign $(15,16)$. The sparkling is a well known phenomenon in amyloidosis. Cardiac MRI examination is the gold standard of imaging method for patients with suspected cardiac amyloidosis. The global subendocardial late gadolinium enhancement is characteristic (17) and correlates well with the prognosis (18).

The prognosis is based on the damage of the affected organs, especially that of the heart. The bad general state, severe postural hypotonia, NYHA III or worse heart failure and the low systolic blood pressure are the clinical features that affect the survival. If both biomarker level is high, the average survival is 7-8 months (19).

As the symptoms are not specific, the diagnosis is often delayed. The later the diagnosis is set up, the worse the prognosis is. In some cases, patients are in a very poor performance status which limitates the diagnostic and therapeutic options. The echocardiograpy is a noninvasive imaging technique which can be used to examine the heart and justify the possibility of cardiac involvement. Moreover, the three-dimensional speckle tracking echocardiography is a new method to the quantitative characterization of wall motions with the help of strain analysis. The motion of the left ventricle can be seen objectively as left ventricular rotation and twist. The left ventricular rigid body rotation can quite often be seen in cardiac amyloidosis. With the informations obtained from the strain analysis, it is easier to understand the cardiac changes and its consequences during the course of the disease. If the possibility of cardiac amyloidosis occurs, further examination must be performed as soon as possible in order to be able to start the adequate therapy.

Going through the litterature, some investigations were missing. It is important to know whether alterations in aortic elasticity is associated with cardiac amyloidosis. 
In cardiac amyloidosis, one of the most severe complication is the heart failure. With the examinations of the functioning of the left ventricle, its rotational characteristics and twist can help to understand the impairment of the heart's function.

Now there are new opportunities to image the mitral annulus and its function by echocardiography, therefore extra informations about its role in compensating to maintain circulation in cardiac amyloidosis-associated functional impairment could be clarified.

The function of the right and the left atrium are essential. The enlargement of the left atrium is found to be an independent predictor of mortality. The right atrium is difficult to assess due to view dependency and geometric difficulties in two-dimensional echocardiography. With three-dimensional examination, now more information can be obtained. 


\section{Aims}

To test whether alterations in echocardiographic ascending aortic elastic properties could be detected in CA patients and to compare their results to age-, gender- and risk factor-matched controls.

To examine left ventricular (LV) rotational mechanics in biopsy-proven CA by threedimensional (3D) speckle-tracking echocardiography (3DSTE).

To compare left atrial (LA) volumetric and functional characteristics between light-chain (AL) CA and HCM by 3DSTE.

To characterize the volumetric and functional properties of the right atrium in AL-CA by 3DSTE.

To compare the size and function of the mitral annulus (MA) between CA patients and agematched controls by 3DSTE. 


\section{Methods}

Patient population. Patients were collected from the Hematology and Cardiology Departments of the 2nd Department of Medicine and Cardiology Center, Albert Szent-Györgyi Clinical Center, Faculty of Medicine, University of Szeged, Hungary. To confirm the diagnosis of CA, biopsy was performed in all cases. The majority of patients were diagnosed with AL type amyloidosis, while two patients had TTR type amyloidosis. The source of the biopsy was myocardium, kidney, gastrointestinal tract, subcutaneous tissue, bone marrow and salivary gland. Demographic characteristics were collected together with data about concomittant diseases (hypertension, diabetes mellitus, hypercholesterinaemia) and relevant laboratory results. Routine echocardiographic examination was performed in all cases including measurement of wall thicknesses and CA was defined in accordance with the current consensus criteria and practices $(20,21)$. None of the CA patients or control subjects consumed coffee or tea within 1 hour before combined echocardiographic and blood pressure measurements. Moreover, none of the CA patients or control subjects was smoker. The American Diabetes Association and World Health Organization criteria were used for definition of diabetes mellitus (DM). Hypertension was defined as either a systolic or a diastolic elevation of the blood pressure $(>140 / 90 \mathrm{mmHg}$ ) or ongoing antihypertensive therapy. Hypercholesterolaemia was defined as total cholesterol level $>5.0 \mathrm{mmol} / \mathrm{l}$ or current treatment with lipid-lowering medications. None of the healthy subjects in the control group had cardiovascular risk factors or any known diseases or received any medications. For cardiac assessment, complete twodimensional Doppler, tissue Doppler echocardiography and 3DSTE were performed in all patients and controls. The present study was designed as a part of the Motion Analysis of the heart and Great vessels bY three-dimensionAl speckle-tRacking echocardiography in Pathological cases (MAGYAR-Path) Study. It has been organized to examine alterations in 3DSTE-derived parameters in different disorders compared to matched healthy controls or other diseases among others ('magyar' means 'Hungarian' in Hungarian language). The study protocol conformed to the ethical guidelines of the 1975 Declaration of Helsinki (and updated versions) and was approved in advance by the local institutional ethical committee. Informed consent was obtained from each subject. 
Two-dimensional echocardiography. Commercially available ultrasound system (Toshiba Artida ${ }^{\mathrm{TM}}$, Toshiba Medical Systems, Tokyo, Japan) equipped with a broadband (1-5 $\mathrm{MHz}$ ) PST-30SBP phased-array transducer was used for the completion of standard transthoracic echocardiographic examinations. Measurements of LV dimensions, volumes and ejection fraction were obtained in accordance with the recommendations of the American Society of Echocardiography (22). The degree of mitral regurgitation (MR) was graded visually by colour Doppler echocardiography.

Assessment of the echocardiographic aortic elastic properties. Aortic elasticity parameters were calculated following a validated method $(23,24)$. During a routine echocardiographic examination in parasternal long-axis view an M-mode image was created at a level of $3 \mathrm{~cm}$ above the aortic valve and systolic and diastolic ascending aortic diameters (SD and DD, respectively) were measured (Figure 1). The American Society of Echocardiography convention as the most accepted border definition criteria was used measuring the leading edge of each layer. The SD and DD were measured at the time of maximum aortic anterior motion and at the peak of the QRS complex, respectively. At the same time, systolic and diastolic blood pressure (BP) values were measured in supine position using an automatic cuff mercury sphygmomanometer on the left arm after 10 minutes of rest.

The following aortic elasticity parameters have been calculated:

- $\quad$ Pulsatile change in aortic diameter $=\mathrm{SD}-\mathrm{DD}$

- $\quad$ Aortic strain $(\mathrm{AS})=(\mathrm{SD}-\mathrm{DD}) / \mathrm{DD}$

- $\quad$ Aortic stiffness index $(\mathrm{ASI})=\ln ($ Systolic BP/Diastolic BP $) /[(\mathrm{SD}-\mathrm{DD}) / \mathrm{DD}]$, where ' 1 'n' is the natural logarithm

Aortic distensibility $(\mathrm{AD})=2 \mathrm{x}(\mathrm{SD}-\mathrm{DD}) /[($ Systolic BP - Diastolic BP $) \times \mathrm{DD}]$ 


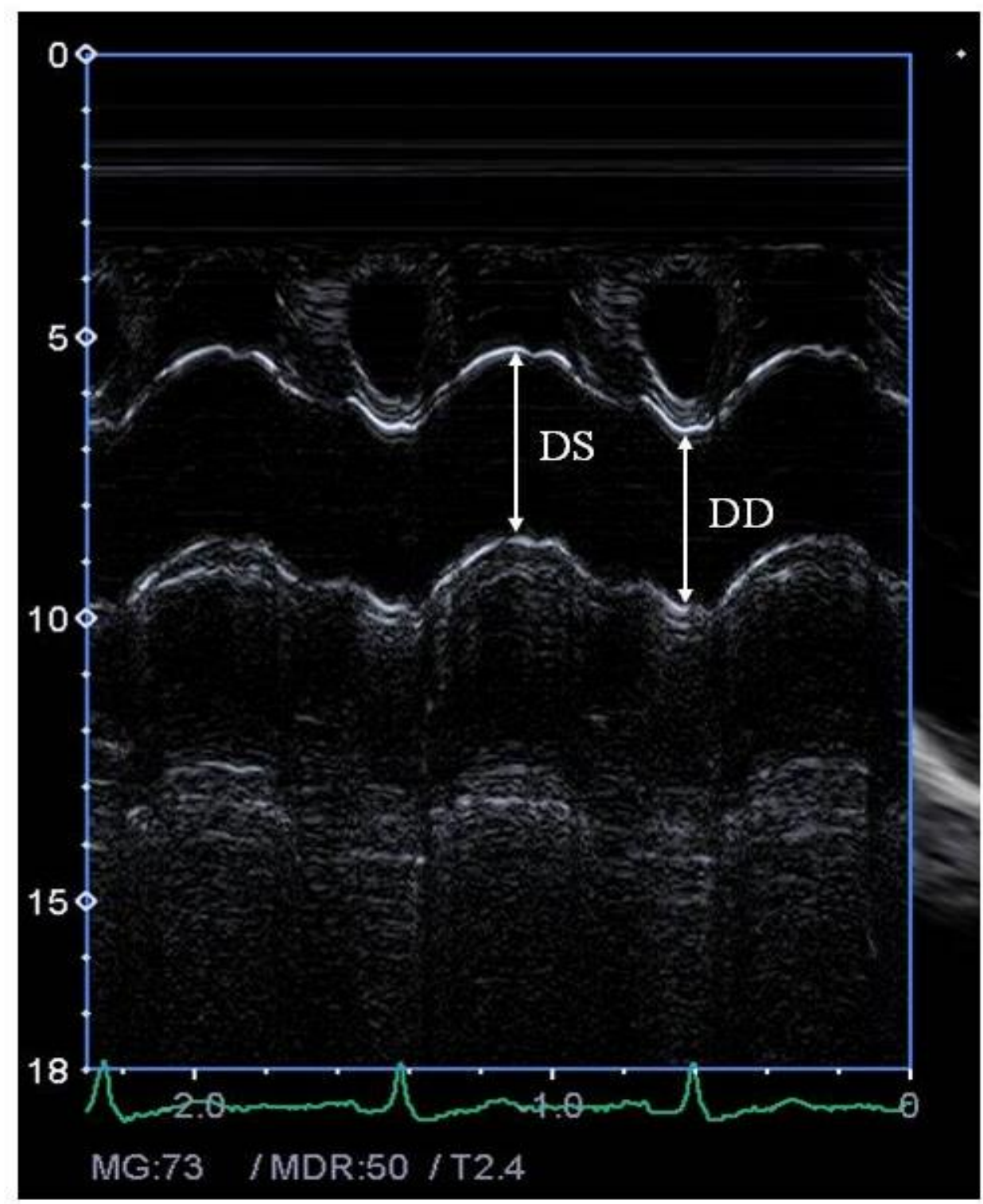

Figure 1. Measurement of systolic (DS) and diastolic (DD) diameters of the ascending aorta are shown on the M-mode tracing obtained at a level $3 \mathrm{~cm}$ above the aortic valve at parasternal long-axis view

Three-dimensional speckle tracking echocardiography-derived data collection. Three-dimensional echocardiographic datasets were acquired with the same Toshiba Artida ${ }^{\mathrm{TM}}$ ultrasound system with a 1-4 MHz PST-25SX matrix phased-array transducer (25). After gain setting optimalisation, wide-angled pictures were recorded, in which 6 wedge-shaped subvolumes were acquired over 6 consecutive cardiac cycles during a single breath-hold. Raw data format was used for further analysis. 
Quantification of the right atrium/left atrium by 3DSTE. 3D Wall Motion Tracking software version 2.7 (Toshiba Medical Systems, Tokyo, Japan) was used for RA/LA quantifications. Each 3D dataset was displayed in a 5-plane view: an apical 4-chamber view, an apical 2-chamber view and 3 short-axis views at different RA/LA levels from the base to the apex. The examiner then set markers in the apical 4- and 2-chamber views; in each plane, one marker was placed on the apex (superior region) and two other markers were placed at the edges of the tricuspid/mitral valve ring. As the next step, the software automatically detected the endocardium, and 3D wall motion-tracking analysis was performed through the entire cardiac cycle. During evaluations, RA/LA appendages and the caval/pulmonary veins were excluded from the RA/LA cavity (Figure 2).

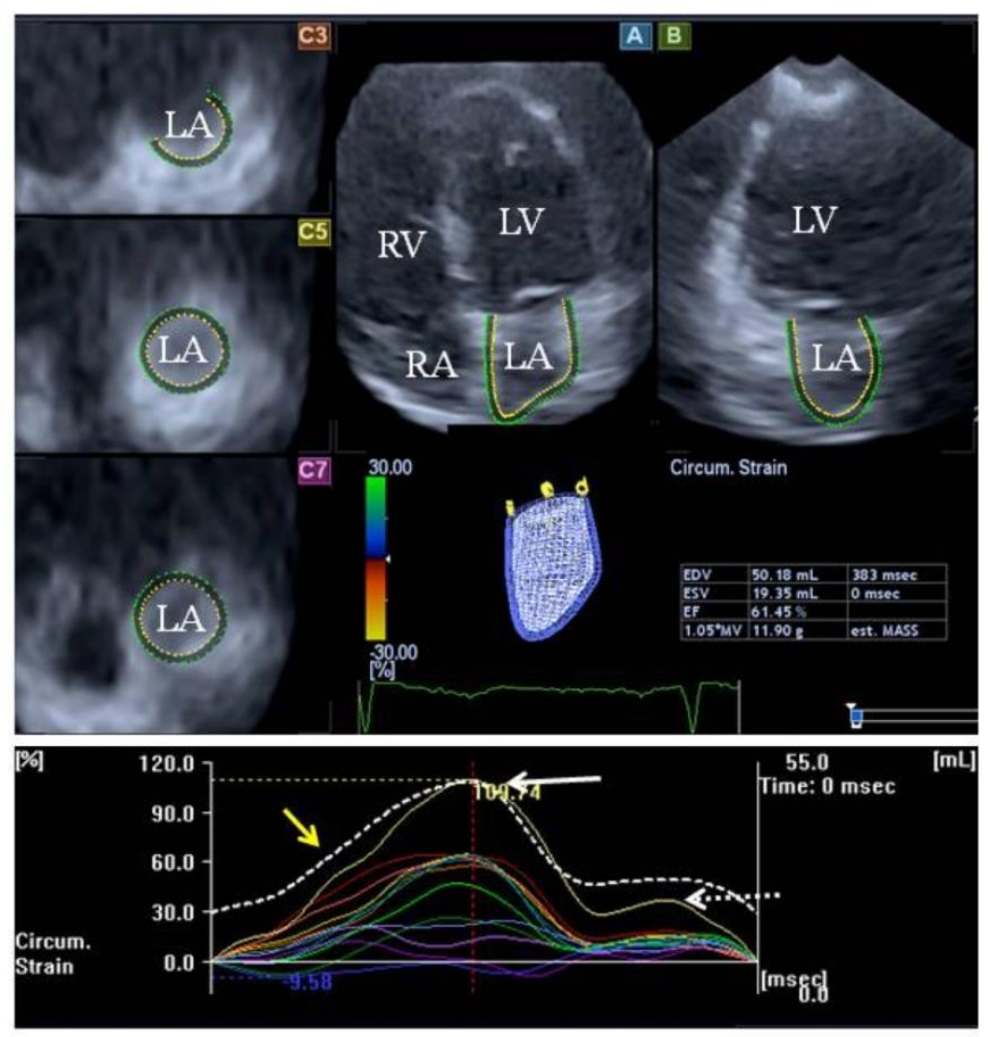

Figure 2. Apical 4-chamber (A) and 2-chamber views (B), and different parasternal shortaxis views at basal (C3), mid (C5) and superior (C7) left atrial regions, extracted from the three-dimensional volume. A three-dimensional wireframe reconstruction of the left atrium based on three-dimensional speckle-tracking echocardiographic analysis together with volumetric data and segmental (circumferential) time-strain curves are also presented. White, dashed and yellow arrows represent segmental (systolic) peak strain, (late-diastolic) strain at atrial contraction and global time-volume curve, respectively. Abbreviations: LA: left atrium; LV: left ventricle; RA: right atrium; RV: right ventricle. 


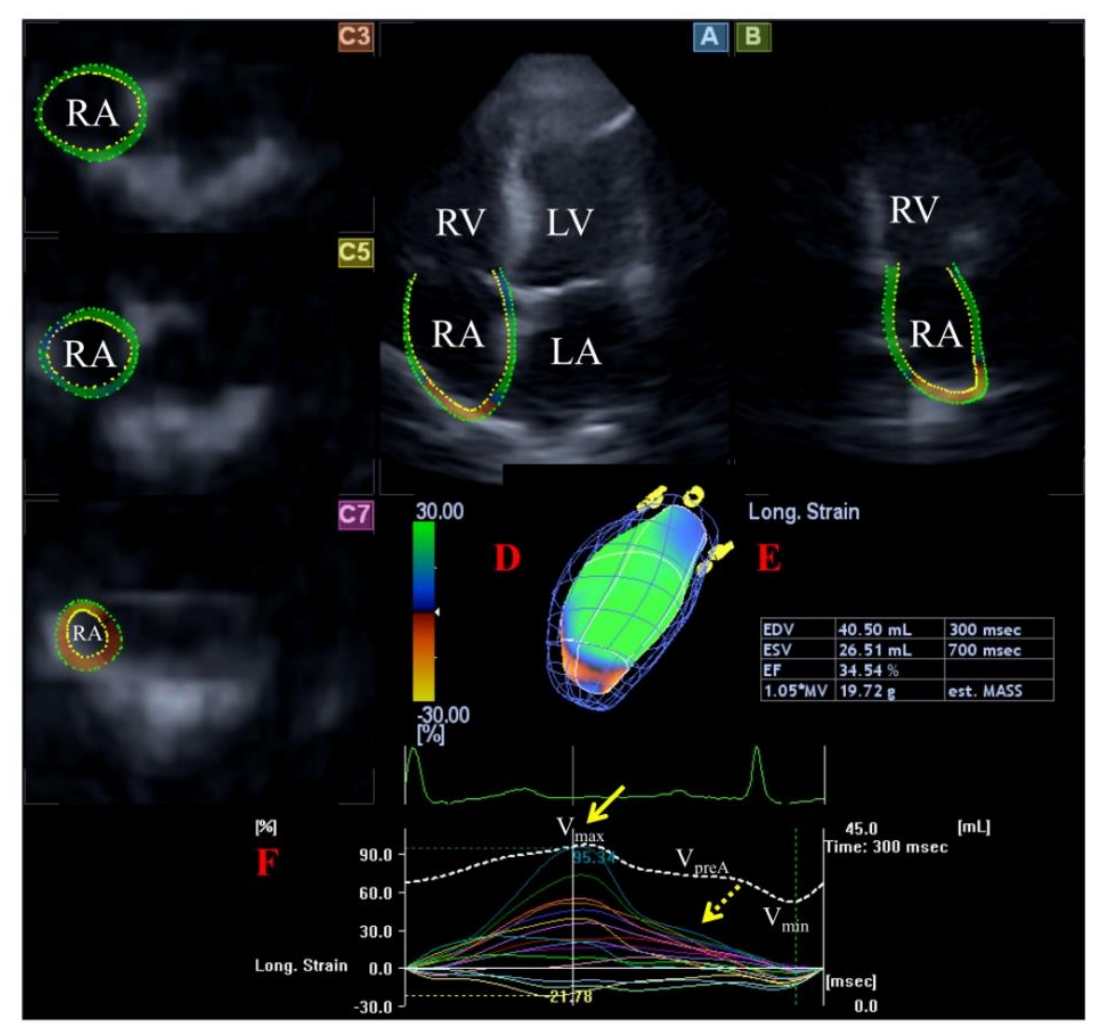

Figure 3. Images from three-dimensional (3D) full-volume dataset showing thre right atrium (RA) are presented: apical four-chamber (A) and two-chamber views (B) and short-axis views at basal (C3), mid- (C5) and superior (C7) RA levels together with a virtual 3D model of the RA (red D) and with RA volumetric data (red E). Time segmental (longitudinal) strain curves of all 16 RA segments (coloured lines) and a time global RA volume change curve respecting cardiac cycle (white dashed line) are also presented (red F). Yellow arrow represents peak RA strain, while yellow dashed arrow represents $R A$ strain at atrial contraction. $V_{\max }, V_{\min }$ and $V_{\text {preA }}$ represent maximum and minimum RA volumes and RA volume at atrial contraction, respectively.

From the acquired 3D echocardiographic datasets, time-global RA/LA volume curves were created allowing the measurement of maximum $\left(\mathrm{V}_{\max }\right)$ and minimum $\left(\mathrm{V}_{\min }\right) \mathrm{RA} / \mathrm{LA}$ volumes and RA/LA volume before atrial contraction $\left(\mathrm{V}_{\text {preA }}\right)$. $\mathrm{V}_{\max }$ was measured just before mitral valve opening at end-systole, while $\mathrm{V}_{\min }$ and $\mathrm{V}_{\text {preA }}$ were measured just before mitral valve closure at end-diastole and at the time of P wave on ECG in early diastole, respectively. The systolic reservoir and diastolic passive (conduit) and active emptying (booster pump) phases of RA/LA function were measured from the RA/LA volumetric datasets. Time-strain curves could also be created at the same time from the same 3D echocardiographic datasets. Unidirectional radial, longitudinal, circumferential and complex area and 3D strains could be also measured. Global strains were calculated by the software, which considered the whole RA/LA, while mean 
segmental strains were obtained as the average of strains of 16 segments. A typical strain curve usually represents two peaks: the first peak indicates the reservoir phase, while the second peak shows characteristics of the booster pump phase of the RA/LA function (Figure 3).

The following features of different phases of RA/LA function were also calculated:

for (systolic) reservoir function:

- Total Atrial Stroke Volume (TASV): $\mathrm{V}_{\max }-\mathrm{V}_{\min }$.

- Total Atrial Emptying Fraction (TAEF): TASV/ $V_{\max } \times 100$.

for (early diastolic) conduit function:

- Passive Atrial Stroke Volume (PASV): $V_{\max }-V_{\text {preA }}$

- Passive Atrial Emptying Fraction (PAEF): PASV/ $V_{\max } \times 100$.

for (late diastolic) active contraction:

- Active Atrial Stroke Volume (AASV): $\mathrm{V}_{\text {preA }}-\mathrm{V}_{\min }$.

- Active Atrial Emptying Fraction (AAEF): AASV/ $V_{\text {preA }} \times 100$.

Quantification of the left ventricle by 3DSTE. Similarly to the above mentioned methodology, a virtual 3D model of the LV was also created following manual definition of the $\mathrm{LV}$ endocardium at the edges of the mitral valve and the LV apex on AP2CH and $\mathrm{AP} 4 \mathrm{CH}$ views. Automatic reconstraction and tracking of the endocardium throughout the cardiac cycle were then obtained. For quantification of 3DSTE-derived global peak apical, midventricular and basal LV rotations were also calculated for each patients (Figure 4). 


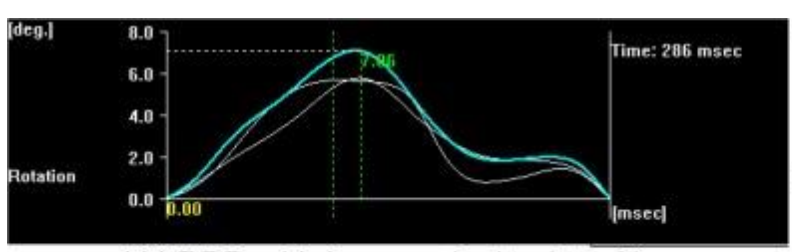

LV-RBR with baso-apical twist $<3^{\circ}$

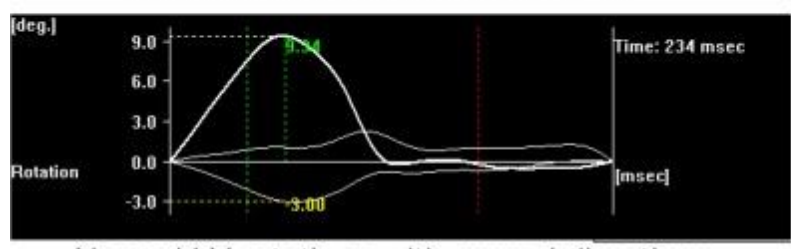

Normal LV rotations with normal directions



LV hyporotations with normal directions



LV hyperrotations with normal directions

Figure 4. Examples of different patterns of left ventricular rotational mechanics in patients with cardiac amyloidosis.

Quantification of the mitral annulus by 3DSTE. Several morphological MA parameters, including diameter, area and perimeter were measured on the Q7 short-axis view at the level of the MA. AP2CH and AP4CH views helped to find optimal endpoints of the MA. Measurements were made both at end-diastole (just before mitral valve closure) and end-systole (just before mitral valve opening). The following measurements were obtained (Figure 5):

Morphological parameters

- MA diameter (MAD), defined as the perpendicular line drawn from the peak of MA curvature to the middle of the straight MA border,

- MA area (MAA), measured by planimetry,

- MA perimeter (MAP), measured by planimetry,

Functional parameters

- MA fractional shortening (MAFS), defined as ([end-diastolic MAD - end-systolic MAD]/enddiastolic MAD) $\times 100$,

- MA fractional area change (MAFAC), defined as ([end-diastolic MAA - end-systolic MAA]/end-diastolic MAA) $\times 100$ 


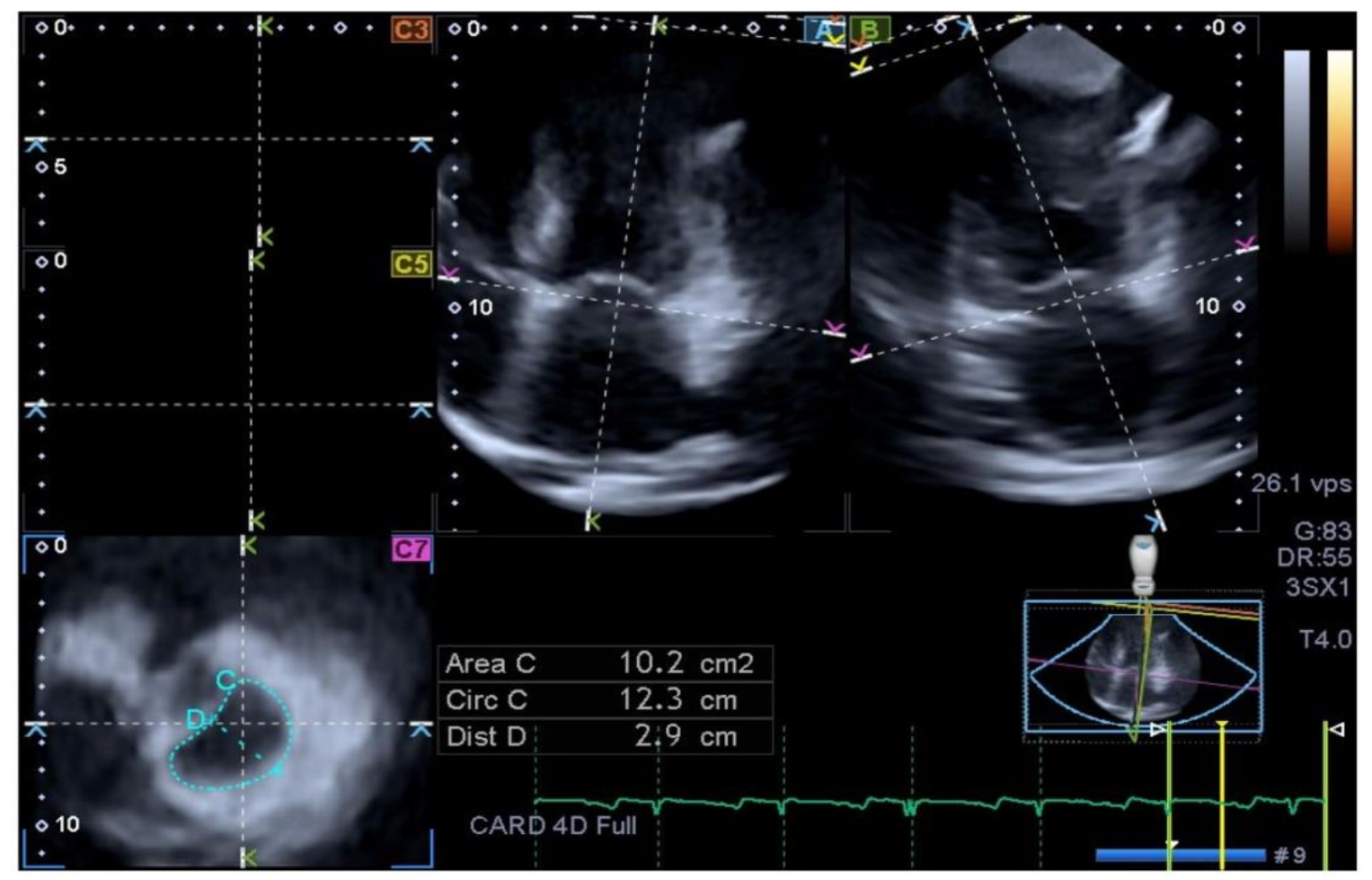

Figure 5. Images from three-dimensional full-volume dataset showing mitral annulus in a patient with cardiac amyloidosis: (A) apical four-chamber view, (B) apical two-chamber view and a cross sectional view at the level of the mitral annulus (C7) optimalized in apical four- and two-chamber views.

Statistical analysis. All data reported are presented as mean \pm standard deviation. A value of $p<0.05$ was considered to be statistically significant. Independent samples Student $t$ test were used to compare continuous variables and chi-square test and Fisher's exact test to compare categorical ones. Numerical correlations were established by a Pearson correlation. MedCalc software was used for statistical calculations (MedCalc, Mariakerke, Belgium). 


\section{Results}

\subsection{Echocardiographic ascending aortic elastic properties in cardiac amyloidosis}

Clinical characteristics. The present study comprised of $19 \mathrm{CA}$ patients from which CA proved to be AL amyloidosis in 17 cases and transthyretin (TTR) amyloidosis in 2 cases. All CA patients alive have been involved into this study at our tertiary center. To confirm the diagnosis of CA biopsy was performed in all cases. The first positive biopsy site was the myocardium in 2 TTR-CA cases and in 3 AL-CA subjects. In the remaining AL-CA cases, kidney was the first positive biopsy site in 5 cases, gastrointestinal tract in 4 cases, skin and subcutaneous tissue in 4 cases, bone marrow in 3 cases and salivary gland in 1 case (there were 2 confirmation sites in 2 patients). Their results were compared to 20 age-, gender and risk factor-matched controls. Blood urea nitrogen and creatinine levels were determined to characterize renal function in CA patients and proved to be $10.7 \pm 9.4 \mathrm{mmol} / \mathrm{l}(3.1-43.9)$ and $119.1 \pm 107$ umol/1 (44-533), respectively, demonstrating 3 cases with mild-moderate and 2 cases with severe renal insufficiency. Clinical data, cardiovascular risk factors and medications of CA patients and matched controls are presented in Table 1. Although none of the classic cardiovascular risk factors differed significantly between the groups, control subjects showed higher BMI and systolic and diastolic BP values at the time of echocardiographic examinations.

Two-dimensional echocardiographic data. Standard 2D echocardiographic data are summarized in Table 2. No wall motion abnormalities were found in any CA patients or healthy subjects. Significant ( $\geq$ grade 3) mitral regurgitation (MR) could not be detected in any of the CA patients or control subjects. Significantly thickened interventricular septum and LV posterior wall, reduced LV ejection fraction and increased E/A suggesting systolic and diastolic dysfunction could be detected in CA patients (Table 2).

Echocardiographic aortic elastic properties. Significantly reduced aortic strain and pulsatile change in aortic diameter and increased aortic stiffness index could be demonstrated in CA patients as compared to matched controls (Table 2). From CA patients 10 were in NYHA I, 3 in NYHA II, 3 in NYHA III and 3 in NYHA IV functional classes. The average ASI differed significantly between CA patients in NYHA classes III-IV as compared to CA patients in classes NYHA I-II $(20.40 \pm 14.80$ vs. $9.05 \pm 8.84, p=0.03)$. None of other LV and aortic parameters showed difference between CA patients in different functional classes. 
Correlations. Significant correlations could be detected between ASI and LV end-diastolic diameter $(r=0.45, p=0.05)$ and thickness of the posterior wall $(r=0.49, p=0.03)$ and interventricular septum $(r=0.46, p=0.05)$ in CA patients. None of other aortic data correlated with any LV parameters in CA patients and in controls.

Table 1. Clinical characteristics of patients with cardiac amyloidosis and that of controls

\begin{tabular}{|c|c|c|c|}
\hline & $\begin{array}{c}\text { CA patients } \\
(\mathbf{n}=19)\end{array}$ & $\begin{array}{c}\text { Controls } \\
(\mathrm{n}=20)\end{array}$ & $\mathbf{p}$ \\
\hline \multicolumn{4}{|l|}{ Clinical data } \\
\hline Age (years) & $63.7 \pm 9.1$ & $59.3 \pm 4.1$ & 0.06 \\
\hline Male gender $(\%)$ & $14(74)$ & $17(85)$ & 0.44 \\
\hline Height (m) & $170.7 \pm 7.7$ & $162.6 \pm 6.0$ & 0.001 \\
\hline Weight (kg) & $76.1 \pm 15.3$ & $89.2 \pm 17.7$ & 0.03 \\
\hline Body mass index $\left(\mathrm{kg} / \mathrm{m}^{2}\right)$ & $26.1 \pm 5.0$ & $33.5 \pm 5.6$ & 0.0003 \\
\hline Diabetes mellitus (\%) & $2(11)$ & $3(15)$ & 1.00 \\
\hline Hypertension (\%) & $12(67)$ & $15(75)$ & 0.72 \\
\hline Hypercholesterolaemia (\%) & $6(33)$ & $8(40)$ & 0.74 \\
\hline \multicolumn{4}{|l|}{ Blood pressure values } \\
\hline Systolic blood pressure $(\mathrm{mmHg})$ & $104.3 \pm 12.9$ & $145.6 \pm 11.9$ & $<0.0001$ \\
\hline Diastolic blood pressure (mmHg) & $69.1 \pm 10.6$ & $89.1 \pm 9.2$ & $<0.0001$ \\
\hline Aortic pulse pressure $(\mathrm{mmHg})$ & $35.3 \pm 10.6$ & $60.0 \pm 10.8$ & $<0.0001$ \\
\hline \multicolumn{4}{|l|}{ Most important medications } \\
\hline$\beta$-blockers $(\%)$ & $8(44)$ & $5(25)$ & 0.31 \\
\hline ACE-inhibitors (\%) & $10(56)$ & $9(45)$ & 0.75 \\
\hline Diuretics $(\%)$ & $13(72)$ & $0(0)$ & 0.0001 \\
\hline
\end{tabular}


Table 2. Two-dimensional echocardiographic data of patients with cardiac amyloidosis and that of controls

\begin{tabular}{lccc}
\hline & $\begin{array}{c}\text { CA patients } \\
(\mathbf{n = 1 9})\end{array}$ & $\begin{array}{c}\text { Controls } \\
(\mathbf{n = 2 0})\end{array}$ & p \\
\hline Two-dimensional echocardiography & & & \\
$\quad$ Left atrial diameter (mm) & $46.3 \pm 7.2$ & $40.2 \pm 10.2$ & 0.10 \\
Left ventricular end-diastolic diameter (mm) & $47.0 \pm 5.2$ & $46.2 \pm 3.8$ & 0.58 \\
Left ventricular end-systolic diameter (mm) & $30.7 \pm 5.2$ & $28.9 \pm 3.9$ & 0.26 \\
Interventricular septum (mm) & $15.1 \pm 3.4$ & $9.9 \pm 1.1$ & $<0.0001$ \\
Left ventricular posterior wall (mm) & $14.2 \pm 2.4$ & $9.7 \pm 1.0$ & $<0.0001$ \\
Left ventricular ejection fraction (\%) & $59.3 \pm 11.7$ & $66.2 \pm 6.7$ & 0.03 \\
Mitral annular plane systolic excursion (mm) & $12.5 \pm 4.4$ & $20.2 \pm 3.5$ & 0.01 \\
Systolic aortic diameter (mm) & $30.6 \pm 4.0$ & $29.8 \pm 3.7$ & 0.56 \\
Diastolic aortic diameter (mm) & $29.1 \pm 3.7$ & $27.6 \pm 3.2$ & 0.22 \\
E/A & $1.89 \pm 1.15$ & $0.88 \pm 0.21$ & 0.0007 \\
Aortic elastic properties & & & \\
Pulsatile change in aortic diameter (mm) & $1.53 \pm 1.08$ & $2.22 \pm 1.04$ & 0.05 \\
Aortic strain (AS) & $0.054 \pm 0.039$ & $0.080 \pm 0.036$ & 0.04 \\
Aortic distensibility (AD) (cm ${ }^{2} /$ dynes $\left.10^{-6}\right)$ & $2.42 \pm 1.49$ & $2.13 \pm 0.88$ & 0.47 \\
Aortic stiffness index (ASI) & $12.6 \pm 10.7$ & $7.5 \pm 3.6$ & 0.05 \\
\hline
\end{tabular}

\subsection{Left ventricular rotational mechanics in biopsy-proven cardiac amyloidosis as assessed by three-dimensional speckle-tracking echocardiography}

Clinical characteristics. Ten patients with CA entered the study. All living CA patients who were treated and managed by the outpatient clinic or the haematology division of our center were involved in the present work. The diagnosis of CA was confirmed by biopsy in all subjects. The first positive biopsy site was myocardium in 4 cases, bone marrow in 1 case, duodenum in 1 case, salivary gland in 1 case, colon in 1 case and kidney in 2 cases in CA patients. CA proved to be AL amyloidosis in 8 cases and transthyretin amyloidosis in 2 cases. Heart involvement was defined as mean LV wall thickness (half of the sum of ventricular septum and posterior wall thickness) $>12 \mathrm{~mm}$ at echocardiography in the absence of other cardiac diseases and/or by biopsy, according to the International Society for Amyloidosis criteria (4). Clinical and 2D echocardiographic characteristics of CA patients are presented in Table 3. 
Three-dimensional speckle-tracking echocardiography. LV rotational characteristics of each CA patients are presented in Figure 6. Although a relatively small number of CA patients were examined, LV basal and apical rotations were in the same clockwise direction in 6 out of 10 CA patients demonstrating near absence of LV twist (LV ,rigid body rotation”, RBR). Apico-basal difference was near 3 or less degrees in 3 patients, and 6-10 degrees in the other 3 subjects with LV-RBR. One another patient showed normal rotational mechanics, while two patients had significant hyporotations and one had significant hyperrotations in normal directions. The mean basal LV rotations were $0.3 \pm 3.8^{\circ}$, while mean apical LV rotations proved to be $7.0 \pm 3.3^{\circ}$ in CA patients.



Figure 6. Rotational characteristics of patients with cardiac amyloidosis (CA) are presented. 
Table 3. Clinical and 2D echocardiographic characteristics of CA patients

\begin{tabular}{lc}
\hline Parameters & $\begin{array}{c}\text { CA patients } \\
(\mathbf{n}=\mathbf{1 0})\end{array}$ \\
\hline Risk factors & $65.3 \pm 11.5$ \\
Age (years) & $6(60)$ \\
Male gender $(\%)$ & $25.5 \pm 4.3$ \\
Body mass index $\left(\mathrm{kg} / \mathrm{m}^{2}\right)$ & $0(0)$ \\
Diabetes mellitus $(\%)$ & $4(40)$ \\
Hypertension $(\%)$ & $2(20)$ \\
Hypercholesterolaemia $(\%)$ & \\
Medications & $3(30)$ \\
$\beta$-blockers $(\%)$ & $4(40)$ \\
ACE-inhibitors $(\%)$ & $5(50)$ \\
Diuretics $(\%)$ & \\
Two-dimensional echocardiography & $48.3 \pm 10.9$ \\
LA diameter (mm) & $45.1 \pm 7.1$ \\
LV end-diastolic diameter (mm) & $98.9 \pm 33.9$ \\
LV end-diastolic volume (ml) & $29.2 \pm 6.9$ \\
LV end-systolic diameter (mm) & $40.5 \pm 18.4$ \\
LV end-systolic volume (ml) & $18.2 \pm 6.3$ \\
Interventricular septum (mm) & $17.3 \pm 6.4$ \\
LV posterior wall (mm) & $58.9 \pm 14.4$ \\
LV ejection fraction $(\%)$ & $2.2 \pm 1.4$ \\
E/A & \\
\hline
\end{tabular}




\subsection{Comparing left atrial volumetric and functional characteristics between light-chain (AL) cardiac amyloidosis and hypertrophic cardiomyopathy by three-dimensional speckle-tracking echocardiography}

Clinical characteristics of AL-CA and HCM patients. The study population consisted of 17 patients with AL-CA, but one patient had been excluded due to inadequate image quality. Therefore, finally the AL-CA group consisted of 16 patients (mean age: $64.0 \pm 9.6$ years, 5 men). Their results were compared with data of 20 age-matched HCM patients (mean age: 59.8 \pm 5.2 years, 10 men) and that of 16 age-matched healthy controls (mean age: $58.2 \pm 7.2$ years, 6 men). The diagnosis of AL-CA was confirmed by biopsy in all CA cases. The first positive biopsy site was the myocardium in 4 cases, the bone marrow in 3 case, the duodenum in 1 case, the salivary gland in 1 case, the colon in 1 case, the rectum 1 case, the kidney in 4 cases and the subcutis in 2 cases in CA patients. AL amyloidosis was diagnosed in patients with multiple myeloma in 13 cases, with plasmacytic dyscrasia in 1 case, it was associated with marginal zone lymphoma in 1 case and with nephrosis syndrome in 2 cases. In those patients, in whom the first biopsy site was not the heart and histopathological report confirmed the diagnosis of AL amyloidosis, two-dimensional (2D) echocardiography was performed. If the involvement of the heart with AL-amyloidosis was suspected according to the data below, three-dimensional (3D) speckle-tracking echocardiography (3DSTE) was performed. The prevalence of cardiovascular risk factors and medications applied in patients with AL-CA/HCM are presented in Table 4. Six out of the $20 \mathrm{HCM}$ patients had significant (>30 $\mathrm{mmHg}$ ) resting peak LV outflow tract gradient (mean: $83.5 \pm 23.0 \mathrm{~mm} \mathrm{Hg}$ ), while $8 \mathrm{HCM}$ patients showed systolic anterior motion of the anterior leaflet of the mitral valve. One HCM patient had implantable cardiac defibrillator due to prophylaxis of malignant arrhythmia and $2 \mathrm{HCM}$ patients had previous percutaneous transluminal septal myocardial ablation. Genetic analysis had been completed in 2 out of $20 \mathrm{HCM}$ patients (10\%). One patient carried a TCAP gene mutation while the other did not carry any sarcomeric gene mutation. The genetic analysis of other patients is currently underway. Magnetic resonance imaging confirm diagnosis of HCM in 5 cases.

Two-dimensional echocardiographic data. Standard 2D echocardiographic data are summarized in Table 4. Significant ( $\geq$ grade 2$)$ MR could be detected in 7 HCM patients (35\%) and in 2 AL-CA patients (13\%). 
3DSTE-derived LA volumetric and volume-based functional parameters. Significantly increased LA volumes could be demonstrated in AL-CA and HCM patients compared to controls. None of the LA stroke volumes showed alterations in AL-CA patients, while TASV and AASV were found to be increased in HCM patients compared to controls and AL-CA patients. Only AAEF was found to be significantly reduced in AL-CA patients as compared to controls. However, emptying fractions of HCM patients were between those parameters of ALCA patients and those of controls.

3DSTE-derived peak global, mean segmental and regional LA strains. Peak global and mean segmental CS, LS and AS showed significant reductions in AL-CA patients compared to controls (Table 5). Differences could be demonstrated in certain global and mean segmental peak strains of AL-CA and HCM patients. Only peak mean segmental LS was significantly decreased in HCM patients compared to controls. Regional peak strains of age-matched ALCA and HCM patients and controls are presented in Table 5.

3DSTE-derived global, mean segmental and regional LA strains at atrial contraction. While no differences could be demonstrated in global and mean segmental strains at atrial contraction between HCM patients and controls, AL-CA patients showed reductions in certain strain parameters as compared to controls and HCM patients. Results of detailed regional analysis are also presented in Table 6. 
Table 4. Clinical and two-dimensional echocardiographic characteristics of light-chain cardiac amyloidosis and hypertrophic cardiomyopathy patients and those of controls

\begin{tabular}{|c|c|c|c|}
\hline & $\begin{array}{c}\text { AL-CA } \\
\text { patients } \\
(n=16) \\
\end{array}$ & $\begin{array}{c}\text { HCM } \\
\text { patients } \\
(n=20)\end{array}$ & $\begin{array}{l}\text { Controls } \\
(n=16)\end{array}$ \\
\hline \multicolumn{4}{|c|}{ Riskfactors } \\
\hline Age (years) & $64.0 \pm 9.6$ & $59.8 \pm 5.2$ & $58.2 \pm 7.2$ \\
\hline Male gender $(\%)$ & $5(31)$ & $10(50)$ & $6(38)$ \\
\hline Diabetes mellitus (\%) & $1(6)$ & $1(5)$ & $0(0)$ \\
\hline Hypertension $(\%)$ & $11(69)$ & $11(55)$ & $0(0)$ \\
\hline Hypercholesterolaemia (\%) & $6(38)$ & $5(25)$ & $0(0)$ \\
\hline \multicolumn{4}{|c|}{ Medications } \\
\hline$\beta$-blockers $(\%)$ & $6(38)$ & $15(75)$ & $0(0)$ \\
\hline ACE-inhibitors (\%) & $8(50)$ & $9(45)$ & $0(0)$ \\
\hline Diuretics $(\%)$ & $11(59)$ & $5(25)$ & $0(0)$ \\
\hline \multicolumn{4}{|c|}{ Two-dimensional echocardiography } \\
\hline LA diameter (mm) & $45.2 \pm 6.9 *$ & $44.9 \pm 4.2 *$ & $35.3 \pm 3.3$ \\
\hline LV end-diastolic diameter (mm) & $46.7 \pm 5.6$ & $46.0 \pm 4.7$ & $47.0 \pm 3.4$ \\
\hline LV end-diastolic volume (ml) & $110.3 \pm 31.9$ & $101.0 \pm 28.4$ & $\begin{array}{c}103.5 \pm \\
17.5\end{array}$ \\
\hline LV end-systolic diameter (mm) & $29.7 \pm 5.3$ & $27.7 \pm 4.7$ & $30.1 \pm 2.8$ \\
\hline LV end-systolic volume $(\mathrm{ml})$ & $41.1 \pm 15.7$ & $29.6 \pm 11.3 \ddagger$ & $35.1 \pm 6.8$ \\
\hline Interventricular septum (mm) & $14.3 \pm 1.8^{*}$ & $21.8 \pm 5.4 t^{*}$ & $9.9 \pm 2.1$ \\
\hline $\mathrm{LV}$ posterior wall $(\mathrm{mm})$ & $13.7 \pm 1.7 *$ & $11.9 \pm 2.1+*$ & $10.2 \pm 2.1$ \\
\hline LV ejection fraction $(\%)$ & $61.3 \pm 12.3$ & $70.9 \pm 7.2+*$ & $65.8 \pm 4.9$ \\
\hline $\mathrm{E} / \mathrm{A}$ & $1.80 \pm 1.01$ & $0.93 \pm 0.36+$ & $1.07 \pm 0.43$ \\
\hline \multicolumn{4}{|c|}{ Three-dimensional speckle-tracking echocardiography } \\
\hline Maximum LA volume $\left(\mathrm{V}_{\max }\right)(\mathrm{ml})$ & $79.6 \pm 26.6^{*}$ & $78.0 \pm 26.6^{*}$ & $55.3 \pm 10.7$ \\
\hline Minimum LA volume $\left(\mathrm{V}_{\min }\right)(\mathrm{ml})$ & $52.7 \pm 23.5^{*}$ & $46.8 \pm 21.7$ & $31.9 \pm 10.0$ \\
\hline LA volume before atrial contraction $\left(\mathrm{V}_{\text {preA }}\right)$ & $69.3 \pm 25.0 *$ & $66.1 \pm 24.1 *$ & $45.7 \pm 11.4$ \\
\hline Total atrial stroke volume (TASV) (ml) & $26.8 \pm 27.1$ & $35.7 \pm 12.3 * t$ & $23.5 \pm 5.4$ \\
\hline Passive atrial stroke volume (PASV) (ml) & $10.3 \pm 6.3$ & $15.1 \pm 7.5^{\circ}$ & $9.7 \pm 3.8$ \\
\hline Active stroke volume (AASV) (ml) & $16.5 \pm 24.2$ & $20.6 \pm 8.2 * t$ & $13.8 \pm 4.8$ \\
\hline Total atrial emptying fraction (TAEF) (\%) & $31.2 \pm 21.1$ & $37.4 \pm 12.3$ & $43.5 \pm 10.8$ \\
\hline Passive atrial emptying fraction (PAEF) $(\%)$ & $13.0 \pm 8.2$ & $16.3 \pm 9.1$ & $18.2 \pm 8.0$ \\
\hline Acive atrial emptying fraction (AAEF) $(\%)$ & $21.5 \pm 20.5^{*}$ & $25.7 \pm 9.2$ & $31.1 \pm 10.5$ \\
\hline
\end{tabular}


Table 5. Comparison of three-dimensional speckle tracking echocardiography-derived global, mean segmental and regional peak left atrial strain parameters in patients with cardiac amyloidosis, hypertrophic cardiomyopathy and in controls

\begin{tabular}{|c|c|c|c|}
\hline & $\begin{array}{c}\text { AL-CA } \\
\text { patients } \\
(n=16)\end{array}$ & $\begin{array}{c}\text { HCM } \\
\text { patients } \\
(\mathbf{n}=\mathbf{2 0}) \\
\end{array}$ & $\begin{array}{c}\text { Controls } \\
(n=16)\end{array}$ \\
\hline \multicolumn{4}{|c|}{ Global LA strain parameters } \\
\hline Radial strain $(\%)$ & $-9.7 \pm 8.7 \dagger$ & $-16.5 \pm 7.1$ & $-8.8 \pm 20.9$ \\
\hline Circumferential strain $(\%)$ & $11.9 \pm 11.1 \dagger^{*}$ & $22.9 \pm 15.5$ & $22.5 \pm 9.3$ \\
\hline Longitudinal strain (\%) & $11.2 \pm 8.4 \dagger *$ & $17.8 \pm 7.0$ & $22.2 \pm 6.3$ \\
\hline Area strain $(\%)$ & $22.0 \pm 19.6^{*} *$ & $40.9 \pm 28.4$ & $48.1 \pm 16.5$ \\
\hline $3 \mathrm{D}$ strain $(\%)$ & $-6.3 \pm 6.2$ & $-9.4 \pm 5.5$ & $-6.2 \pm 13.5$ \\
\hline \multicolumn{4}{|c|}{ Mean segmental LA strain parameters } \\
\hline Radial strain $(\%)$ & $-13.2 \pm 8.4 \dagger$ & $-20.6 \pm 6.8$ & $-11.8 \pm 19.7$ \\
\hline Circumferential strain (\%) & $15.1 \pm 10.1 \dagger^{*}$ & $27.1 \pm 15.9$ & $26.8 \pm 11.5$ \\
\hline Longitudinal strain (\%) & $13.4 \pm 8.5 \dagger *$ & $19.7 \pm 7.2 *$ & $25.3 \pm 6.0$ \\
\hline Area strain $(\%)$ & $28.5 \pm 18.4 \dagger^{*}$ & $48.9 \pm 28.3$ & $53.4 \pm 18.0$ \\
\hline 3D strain $(\%)$ & $-9.8 \pm 6.3 \dagger$ & $-14.3 \pm 5.9$ & $-9.0 \pm 14.2$ \\
\hline \multicolumn{4}{|c|}{ Regional LA strain parameters } \\
\hline Basal radial strain $(\%)$ & $-10.9 \pm 5.81 \dagger$ & $-17.2 \pm 6.0$ & $-11.5 \pm 26.3$ \\
\hline Midatrial radial strain (\%) & $-15.0 \pm 10.4$ & $-20.8 \pm 7.1$ & $-10.3 \pm 21.6$ \\
\hline Superior radial strain $(\%)$ & $-14.1 \pm 13.0 \dagger$ & $-25.4 \pm 14.8^{*}$ & $-8.5 \pm 22.4$ \\
\hline Basal circumferential strain (\%) & $14.3 \pm 12.0 \dagger^{*}$ & $25.2 \pm 13.7$ & $32.9 \pm 9.5$ \\
\hline Midatrial circumferential strain (\%) & $13.7 \pm 11.2 \dagger^{*}$ & $24.4 \pm 16.0$ & $23.7 \pm 7.4$ \\
\hline Superior circumferential strain (\%) & $18.8 \pm 13.1$ & $34.0 \pm 29.2$ & $24.9 \pm 18.6$ \\
\hline Basal longitudinal strain $(\%)$ & $8.5 \pm 6.3 \dagger^{*}$ & $14.4 \pm 7.2$ & $16.5 \pm 8.3$ \\
\hline Midatrial longitudinal strain (\%) & $17.2 \pm 11.8^{*}$ & $24.2 \pm 9.1^{*}$ & $36.8 \pm 11.6$ \\
\hline Superior longitudinal strain (\%) & $14.8 \pm 13.0$ & $21.3 \pm 16.1$ & $20.9 \pm 9.9$ \\
\hline Basal area strain $(\%)$ & $19.0 \pm 13.2 \dagger^{*}$ & $36.7 \pm 19.2$ & $46.6 \pm 17.4$ \\
\hline Midatrial area strain $(\%)$ & $31.2 \pm 25.2 \dagger^{*}$ & $49.1 \pm 25.1$ & $63.4 \pm 20.0$ \\
\hline Superior area strain $(\%)$ & $34.8 \pm 28.9$ & $66.7 \pm 63.9$ & $54.0 \pm 39.2$ \\
\hline Basal 3D strain (\%) & $-8.7 \pm 4.7 \dagger$ & $-13.2 \pm 5.4$ & $-8.8 \pm 21.2$ \\
\hline Midatrial 3D strain (\%) & $-11.0 \pm 8.4$ & $-13.5 \pm 6.1$ & $-8.2 \pm 14.3$ \\
\hline Superior 3D strain $(\%)$ & $-9.6 \pm 9.1 \dagger$ & $-17.1 \pm 12.0 *$ & $-6.7 \pm 14.5$ \\
\hline
\end{tabular}


Table 6. Comparison of three-dimensional speckle tracking echocardiography-derived global, mean segmental and regional left atrial strain parameters at atrial contraction in patients with cardiac amyloidosis, hypertrophic cardiomyopathy and in controls

\begin{tabular}{|c|c|c|c|}
\hline & $\begin{array}{c}\text { AL-CA } \\
\text { patients } \\
(n=16)\end{array}$ & $\begin{array}{c}\text { HCM } \\
\text { patients } \\
(n=20)\end{array}$ & $\begin{array}{c}\text { Controls } \\
(n=16)\end{array}$ \\
\hline \multicolumn{4}{|c|}{ Global LA strain parameters } \\
\hline Radial strain $(\%)$ & $-4.4 \pm 5.5$ & $-7.2 \pm 7.7$ & $-7.9 \pm 6.4$ \\
\hline Circumferential strain (\%) & $5.3 \pm 6.5$ & $11.2 \pm 10.5$ & $11.0 \pm 8.6$ \\
\hline Longitudinal strain $(\%)$ & $3.8 \pm 4.3$ & $5.3 \pm 4.8$ & $8.0 \pm 6.7$ \\
\hline Area strain $(\%)$ & $9.1 \pm 11.0 *$ & $17.7 \pm 17.1$ & $18.1 \pm 13.4$ \\
\hline 3D strain $(\%)$ & $-2.6 \pm 5.3$ & $-5.5 \pm 6.3$ & $-5.9 \pm 4.6$ \\
\hline \multicolumn{4}{|c|}{ Mean segmental LA strain parameters } \\
\hline Radial strain $(\%)$ & $-7.5 \pm 5.9$ & $-9.7 \pm 6.1$ & $-10.5 \pm 4.6$ \\
\hline Circumferential strain $(\%)$ & $7.2 \pm 6.8 \dagger$ & $13.4 \pm 9.5$ & $11.7 \pm 7.6$ \\
\hline Longitudinal strain $(\%)$ & $6.5 \pm 5.2$ & $8.3 \pm 6.6$ & $9.3 \pm 5.0$ \\
\hline Area strain $(\%)$ & $11.9 \pm 11.0 \div *$ & $22.3 \pm 16.9$ & $20.1 \pm 13.5$ \\
\hline 3D strain $(\%)$ & $-4.9 \pm 4.7 *$ & $-7.2 \pm 5.1$ & $-8.22 \pm 3.7$ \\
\hline \multicolumn{4}{|c|}{ Regional LA strain parameters } \\
\hline Basal radial strain $(\%)$ & $-6.3 \pm 4.9 *$ & $-8.4 \pm 4.1$ & $-11.5 \pm 5.3$ \\
\hline Midatrial radial strain $(\%)$ & $-7.9- \pm 6.4$ & $-9.4 \pm 6.0$ & $-10.0 \pm 4.3$ \\
\hline Superior radial strain $(\%)$ & $-8.9 \pm 10.8$ & $-11.9 \pm 12.0$ & $-9.6 \pm 7.6$ \\
\hline Basal circumferential strain $(\%)$ & $7.9 \pm 8.5 \dagger *$ & $15.0 \pm 8.8$ & $16.4 \pm 8.4$ \\
\hline Midatrial circumferential strain $(\%)$ & $6.3 \pm 6.6$ & $10.5 \pm 8.4$ & $10.0 \pm 7.3$ \\
\hline Superior circumferential strain (\%) & $7.8 \pm 7.1$ & $15.8 \pm 18.2$ & $7.9 \pm 14.5$ \\
\hline Basal longitudinal strain (\%) & $2.8 \pm 3.0+*$ & $6.4 \pm 4.3$ & $7.2 \pm 6.1$ \\
\hline Midatrial longitudinal strain (\%) & $8.7 \pm 7.3$ & $8.6 \pm 3.9$ & $11.9 \pm 7.9$ \\
\hline Superior longitudinal strain (\%) & $7.3 \pm 7.5$ & $8.5 \pm 14.0$ & $8.6 \pm 6.5$ \\
\hline Basal area strain $(\%)$ & $9.6 \pm 9.1+*$ & $20.9 \pm 12.9$ & $21.0 \pm 9.5$ \\
\hline Midatrial area strain $(\%)$ & $13.0 \pm 13.0$ & $19.2 \pm 11.3$ & $23.2 \pm 15.1$ \\
\hline Superior area strain $(\%)$ & $13.4 \pm 14.9$ & $29.2 \pm 43.5$ & $17.4 \pm 28.7$ \\
\hline Basal 3D strain (\%) & $-4.5 \pm 3.8^{*}$ & $-6.8 \pm 4.3 *$ & $-10.8 \pm 4.5$ \\
\hline Midatrial 3D strain $(\%)$ & $-5.2 \pm 5.6$ & $-6.7 \pm 5.1$ & $-6.4 \pm 3.0$ \\
\hline Superior 3D strain (\%) & $-5.2 \pm 7.9$ & $-8.8 \pm 9.5$ & $-7.22 \pm 6.2$ \\
\hline
\end{tabular}




\subsection{Characterizing volumetric and functional properties of the right atrium in light chain} (AL) cardiac amyloidosis by three-dimensional speckle-tracking echocardiography

Patient population. A total of 16 patients (mean age: $64.5 \pm 10.1$ years, 11 males) with biopsyproven AL-CA were examined. Their results were compared to that of 15 age- and gendermatched healthy controls (mean age: $58.9 \pm 6.9$ years, 8 males). Baseline demographic characteristics of patients and controls are presented in Table 7. CA was defined in accordance with the current consensus criteria and practices ${ }^{13,14}$. None of the patients with AL-CA was on anticoagulant treatment, but 2 of them received acetylsalicylic acid. Five patients received $\beta$ blockers, 7 patients were on angiotensine-converting enzyme inhibitors, while 11 patients took diuretics. The source of the biopsy was the bone marrow in 3 patients, the subcutis in 3 patients, the kidney in 5 patients, the heart in 3 patients, the gastrointestinal tract in 4 patients and the salivary gland in 1 patient. In 3 cases, samples were collected from more than 1 organ. In 11 out of 16 AL-CA patients, the diagnosis of myeloma multiplex was confirmed. In 1 case, no treatment information was available. In all other cases, different types of chemotherapy or immunomodulatory treatment were administered. None of the healthy subjects in the control group had cardiovascular risk factors or any known diseases or received any medications. For cardiac evaluation, complete two-dimensional (2D) Doppler, tissue Doppler echocardiography, 3DSTE and N-terminal pro-B natriuretic pertide (NT-proBNP) level assessment were performed in all patients and controls.

Two-dimensional Doppler echocardiographic and NT-proBNP data. Significantly increased left atrial diameter, interventricular septum (IVS) and left ventricular (LV) posterior wall could be demonstrated in AL-CA patients as compared to matched controls (Table 7). Significant differences could be detected between AL-CA patients and matched controls in tricuspid annular plane systolic excursion $(16.7 \pm 3.1 \mathrm{~mm}$ vs. $20.0 \pm 1.8 \mathrm{~mm}, \mathrm{p}=0.05)$ and RV fractional area change $(32.3 \pm 5.3 \%$ vs. $39.2 \pm 3.5 \%, p=0.04)$. Significant ( $\geq$ grade 3$)$ mitral regurgitation could not be detected in any of the patients or control subjects. Only 1 patient with AL-CA had grade 4 tricuspid regurgitation. NT-proBNP level proved to be $9983 \pm 11101 \mathrm{U} / 1$ in AL-CA patients.

Three-dimensional speckle tracking echocardiographic data. Significant differences could be demonstrated in all RA volumes respecting the cardiac cycle. Total and active atrial 
emptying fractions were significantly decreased in AL-CA patients, while RA stroke volumes did not differ between the groups examined (Table 8). Peak global and mean segmental area strains proved to be reduced in AL-CA patients as compared to that of matched controls. Midatrial segmental circumferential, longitudinal and area strains together with some basal strains proved to be reduced in patients with AL-CA (Tables 9-10). Global longitudinal and area strains at atrial contraction were impaired in AL-CA patients together with midatrial segmental circumferential and area strains (Tables 11-12). These results could suggest impaired longitudinal and circumferential RA function in reservoir and active contraction phases of the RA function. Alterations in segmental RA strains could suggest non-uniformity of RA dysfunction in these cases.

Table 7. Baseline demographic and two-dimensional echocardiographic data in patients with cardiac amyloidosis and matched controls

\begin{tabular}{lccc}
\hline & $\begin{array}{c}\text { AL-CA } \\
\text { patients } \\
(\mathbf{n = 1 6})\end{array}$ & $\begin{array}{c}\text { Controls } \\
(\mathbf{n = 1 5})\end{array}$ & p-value \\
\hline Risk factors & $64.5 \pm 10.1$ & $58.9 \pm 6.9$ & 0.08 \\
Age (years) & $11(69)$ & $8(53)$ & 0.47 \\
Male gender (\%) & $11(69)$ & $0(0)$ & $<0.0001$ \\
Hypertension (\%) & $1(6)$ & $0(0)$ & 0.46 \\
Diabetes mellitus (\%) & $6(38)$ & $0(0)$ & 0.02 \\
Hypercholesterolaemia (\%) & & & \\
Two-dimensional echocardiography & $45.1 \pm 6.7$ & $36.6 \pm 4.00$ & $<0.0001$ \\
LA diameter (mm) & $47.1 \pm 5.7$ & $47.3 \pm 3.2$ & 0.93 \\
LV end-diastolic diameter (mm) & $112.9 \pm 31.9$ & $104.9 \pm 16.7$ & 0.42 \\
LV end-diastolic volume (ml) & $30.0 \pm 5.3$ & $30.4 \pm 2.8$ & 0.80 \\
LV end-systolic diameter (mm) & $41.7 \pm 15.4$ & $35.7 \pm 6.9$ & 0.11 \\
LV end-systolic volume (ml) & $14.2 \pm 1.9$ & $10.4 \pm 1.7$ & $<0.0001$ \\
Interventricular septum (mm) & $13.6 \pm 1.7$ & $10.4 \pm 1.9$ & 0.0003 \\
LV posterior wall (mm) & $61.5 \pm 11.9$ & $65.7 \pm 4.8$ & 0.21 \\
LV ejection fraction $(\%)$ & $1.71 \pm 1.08$ & $1.00 \pm 0.45$ & 0.14 \\
E/A & & & \\
\hline
\end{tabular}


Table 8. Comparison of 3DSTE-derived volumetric and volume-based functional right atrial parameters in patients with cardiac amyloidosis and in matched controls

\begin{tabular}{lccc}
\hline & $\begin{array}{c}\text { AL-CA } \\
\text { patients } \\
(\mathbf{n = 1 6 )}\end{array}$ & $\begin{array}{c}\text { Controls } \\
(\mathbf{n = 1 5})\end{array}$ & p-value \\
\hline Calculated Volumes & & & \\
$\quad$ Vmax (ml) & $85.0 \pm 40.2$ & $43.0 \pm 13.2$ & $<0.0001$ \\
Vmin (ml) & $69.8 \pm 37.3$ & $30.8 \pm 9.2$ & $<0.0001$ \\
VpreA (ml) & $79.2 \pm 41.0$ & $38.2 \pm 12.8$ & $<0.0001$ \\
Stroke Volumes & $15.2 \pm 9.2$ & $12.2 \pm 7.3$ & 0.40 \\
TASV (ml) & $5.8 \pm 5.1$ & $4.8 \pm 3.1$ & 0.98 \\
PASV (ml) & $9.4 \pm 8.6$ & $7.4 \pm 5.9$ & 0.47 \\
AASV (ml) & $19.2 \pm 9.3$ & $27.9 \pm 10.7$ & 0.02 \\
Emptying fractions & $7.9 \pm 8.0$ & $11.5 \pm 6.8$ & 0.07 \\
TAEF (\%) & $12.1 \pm 8.1$ & $18.6 \pm 9.8$ & 0.05 \\
PAEF (\%) & & & \\
AAEF (\%) & & & \\
\hline
\end{tabular}

Table 9. Comparison of 3DSTE-derived peak global and segmental peak right atrial strain parameters in patients with cardiac amyloidosis and in matched controls

\begin{tabular}{lccc}
\hline & $\begin{array}{c}\text { AL-CA } \\
\text { patients } \\
(\mathbf{n = 1 6})\end{array}$ & $\begin{array}{c}\text { Controls } \\
(\mathbf{n = 1 5})\end{array}$ & p-value \\
\hline Peak global strain & & & \\
RS (\%) & $-13.8 \pm 8.8$ & $-15.1 \pm 7.2$ & 0.52 \\
CS (\%) & $7.1 \pm 5.7$ & $10.7 \pm 9.6$ & 0.21 \\
LS (\%) & $12.4 \pm 7.8$ & $16.8 \pm 9.9$ & 0.18 \\
3DS (\%) & $-6.9 \pm 6.2$ & $-8.1 \pm 4.8$ & 0.55 \\
AS (\%) & $16.7 \pm 10.3$ & $31.2 \pm 19.4$ & 0.01 \\
Peak mean segmental strain & & & \\
RS (\%) & $-17.1 \pm 8.8$ & $-18.9 \pm 6.6$ & 0.54 \\
CS (\%) & $12.2 \pm 6.3$ & $16.0 \pm 9.2$ & 0.19 \\
LS(\%) & $16.1 \pm 7.3$ & $21.2 \pm 9.6$ & 0.10 \\
3DS (\%) & $-11.5 \pm 6.1$ & $-12.6 \pm 4.7$ & 0.60 \\
AS (\%) & $24.3 \pm 11.1$ & $38.6 \pm 17.6$ & 0.01 \\
\hline
\end{tabular}


Table 10. Comparison of 3DSTE-derived peak segmental right atrial strain parameters in patients with cardiac amyloidosis and in matched controls

\begin{tabular}{lccc}
\hline & $\begin{array}{c}\text { AL-CA } \\
\text { patients } \\
(\mathbf{n = 1 6 )}\end{array}$ & $\begin{array}{c}\text { Controls } \\
(\mathbf{n = 1 5})\end{array}$ & p-value \\
\hline RS basal (\%) & $-16.3 \pm 10.2$ & $-16.8 \pm 5.7$ & 0.87 \\
RS mid (\%) & $-14.9 \pm 7.7$ & $-18.5 \pm 7.9$ & 0.21 \\
RS superior (\%) & $-21.7 \pm 16.5$ & $-22.5 \pm 11.9$ & 0.87 \\
CS basal (\%) & $10.2 \pm 4.9$ & $15.1 \pm 7.2$ & 0.03 \\
CS mid (\%) & $7.9 \pm 5.7$ & $13.1 \pm 6.9$ & 0.02 \\
CS superior (\%) & $21.8 \pm 16.7$ & $20.8 \pm 21.9$ & 0.53 \\
LS basal (\%) & $17.6 \pm 8.6$ & $24.4 \pm 13.4$ & 0.19 \\
LS mid (\%) & $18.0 \pm 13.3$ & $30.7 \pm 13.1$ & 0.01 \\
LS superior (\%) & $10.9 \pm 10.5$ & $16.8 \pm 9.9$ & 0.07 \\
3DS basal (\%) & $-11.6 \pm 7.2$ & $-11.2 \pm 5.3$ & 0.86 \\
3DS mid (\%) & $-9.6 \pm 5.6$ & $-12.0 \pm 5.9$ & 0.24 \\
3DS superior (\%) & $-14.3 \pm 10.8$ & $-15.4 \pm 9.3$ & 0.77 \\
AS basal (\%) & $19.9 \pm 9.1$ & $30.1 \pm 12.7$ & 0.02 \\
AS mid (\%) & $21.9 \pm 15.9$ & $41.0 \pm 15.4$ & 0.002 \\
AS superior (\%) & $34.4 \pm 30.9$ & $47.9 \pm 48.3$ & 0.66 \\
\hline
\end{tabular}

Table 11. Comparison of 3DSTE-derived global and segmental peak right atrial strain parameters at atrial contraction in patients with cardiac amyloidosis and in matched controls

\begin{tabular}{lccc}
\hline & $\begin{array}{c}\text { AL-CA } \\
\text { patients } \\
(\mathbf{n = 1 6 )}\end{array}$ & $\begin{array}{c}\text { Controls } \\
(\mathbf{n = 1 5})\end{array}$ & p-value \\
\hline Global strain at atrial contraction & & & \\
RS (\%) & $-6.4 \pm 6.7$ & $-6.2 \pm 6.1$ & 0.93 \\
CS (\%) & $10.6 \pm 11.9$ & $7.8 \pm 8.5$ & 0.47 \\
LS (\%) & $4.0 \pm 5.2$ & $8.2 \pm 5.5$ & 0.02 \\
3DS (\%) & $-2.8 \pm 4.9$ & $-3.6 \pm 4.4$ & 0.62 \\
AS (\%) & $7.8 \pm 8.1$ & $15.9 \pm 10.3$ & 0.03 \\
Mean segmental strain at atrial & & & \\
contraction & & & \\
RS (\%) & $-8.5 \pm 6.0$ & $-8.5 \pm 4.8$ & 0.99 \\
CS (\%) & $5.3 \pm 6.2$ & $8.6 \pm 7.3$ & 0.10 \\
LS (\%) & $6.5 \pm 4.0$ & $9.0 \pm 5.7$ & 0.20 \\
3DS (\%) & $-5.3 \pm 4.6$ & $-6.2 \pm 4.5$ & 0.57 \\
AS (\%) & $11.2 \pm 6.8$ & $17.2 \pm 12.3$ & 0.11 \\
\hline
\end{tabular}

Table 12. Comparison of 3DSTE-derived segmental right atrial strain parameters at atrial contraction in patients with cardiac amyloidosis and in matched controls 


\begin{tabular}{lccc}
\hline & $\begin{array}{c}\text { AL-CA } \\
\text { patients } \\
(\mathbf{n = 1 6})\end{array}$ & $\begin{array}{c}\text { Controls } \\
(\mathbf{n = 1 5})\end{array}$ & p-value \\
\hline RS basal (\%) & $-9.6 \pm 9.4$ & $-8.5 \pm 5.7$ & 0.72 \\
RS mid (\%) & $-7.2 \pm 5.5$ & $-7.5 \pm 4.5$ & 0.89 \\
RS superior (\%) & $-9.0 \pm 8.2$ & $-10.2 \pm 7.5$ & 0.67 \\
CS basal (\%) & $4.6 \pm 4.4$ & $10.1 \pm 10.5$ & 0.07 \\
CS mid (\%) & $3.6 \pm 4.4$ & $8.4 \pm 6.2$ & 0.02 \\
CS superior (\%) & $10.6 \pm 11.9$ & $7.4 \pm 9.8$ & 0.42 \\
LS basal (\%) & $7.7 \pm 4.0$ & $8.9 \pm 6.3$ & 0.53 \\
LS mid (\%) & $6.8 \pm 6.9$ & $10.6 \pm 7.3$ & 0.12 \\
LS superior (\%) & $4.1 \pm 5.7$ & $7.0 \pm 7.7$ & 0.20 \\
3DS basal(\%) & $-5.4 \pm 7.0$ & $-6.0 \pm 5.2$ & 0.81 \\
3DS mid(\%) & $-4.2 \pm 4.1$ & $-6.0 \pm 4.5$ & 0.27 \\
3DS superior (\%) & $-6.8 \pm 6.9$ & $-7.1 \pm 6.5$ & 0.90 \\
AS basal (\%) & $9.9 \pm 5.4$ & $16.0 \pm 10.6$ & 0.06 \\
AS mid (\%) & $9.4 \pm 9.1$ & $18.2 \pm 12.4$ & 0.03 \\
AS superior $(\%)$ & $15.9 \pm 19.8$ & $17.2 \pm 22.3$ & 0.87 \\
\hline
\end{tabular}

4.5. Featuring the size and function of the mitral annulus in cardiac amyloidosis by threedimensional speckle-tracking echocardiography

Patient population. A total of 17 patients with CA underwent two-dimensional Doppler echocardiography extended with 3DSTE successfully. Their results were compared to 26 ageand gender-matched healthy controls. All living CA patients who were treated and managed by the outpatient clinic or the haematology division of our center were involved in the present work. The diagnosis of CA was confirmed by biopsy in all subjects. The first positive biopsy site was the myocardium in 4 cases, bone marrow in 1 case, duodenum in 1 case, salivary gland in 1 case, colon in 1 case, rectum in 1 case, skin and subcutaneous tissue in 3 cases and kidney in 5 cases in CA patients. CA proved to be $\mathrm{AL}$ amyloidosis in 16 cases and transthyretin amyloidosis in 1 case.

Demographic and two-dimensional echocardiographic data. We have found significant differences in left atrial size, interventricular septum thickness and posterior wall thickness between CA patients and healthy control subjects (Table 13). None of 17 CA patients and matched controls had significant (grade 3-4) MR or had atrial fibrillation in their medical history. Grade 0,1 and 2 MR could be detected in 6,10 and 1 cases in the CA patient group, 
respectively. Among control subjects, 16 and 10 cases had grade 0 and 1 mitral regurgitations, respectively.

3DSTE-derived MA parameters. Significantly enlarged diastolic and systolic MA diameter, MA area and MA perimeter could be demonstrated together with impaired MAFAC and MAFS in CA patients as compared to age-matched healthy controls (Table 14).

MA function and $\mathrm{LV}$ function. $\mathrm{MAFS}_{3 \mathrm{D}}$ significantly correlated with $\mathrm{LVEF}_{2 \mathrm{D}}$ in $\mathrm{CA}$ patients $(\mathrm{r}=0.62, \mathrm{p}=0.009)$. MAFS $3 \mathrm{D}$ did not correlate with $\mathrm{LVEF}_{2 \mathrm{D}}$ in control subjects. MAFAC $3 \mathrm{D}$ did not correlate significantly either in control or in CA patients. On regression analyses, grade of MR, E/A and E/E' were not found to be independent predictors of MAFAC and MAFS in this CA population.

Table 13. Baseline demographic and two-dimensional echocardiographic data in patients with cardiac amyloidosis and controls

\begin{tabular}{lccc}
\hline & $\begin{array}{c}\text { CA } \\
\text { patients } \\
(\mathbf{n = 1 7 )}\end{array}$ & $\begin{array}{c}\text { Controls } \\
(\mathbf{n = 2 6})\end{array}$ & $\begin{array}{c}\mathbf{p} \\
\text { value }\end{array}$ \\
\hline Risk factors & & & \\
Age (years) & $64.2 \pm 9.8$ & $59.0 \pm 8.2$ & 0.07 \\
Male gender (\%) & $12(71)$ & $13(50)$ & 0.22 \\
Hypertension (\%) & $11(65)$ & $0(0)$ & $<0.001$ \\
Diabetes mellitus (\%) & $1(6)$ & $0(0)$ & 1.00 \\
Hypercholesterolaemia (\%) & $6(35)$ & $0(0)$ & 0.02 \\
Two-dimensional echocardiography & & & \\
LA diameter (mm) & $45.6 \pm 6.8$ & $37.7 \pm 4.9$ & $<0.001$ \\
LV end-diastolic diameter (mm) & $47.1 \pm 5.5$ & $46.2 \pm 3.7$ & 0.57 \\
LV end-diastolic volume (ml) & $111.6 \pm 31.1$ & $100.5 \pm 19.4$ & 0.17 \\
LV end-systolic diameter (mm) & $30.3 \pm 5.3$ & $29.7 \pm 2.8$ & 0.71 \\
LV end-systolic volume (ml) & $42.1 \pm 15.0$ & $34.3 \pm 8.2$ & 0.04 \\
Interventricular septum (mm) & $14.4 \pm 2.0$ & $9.9 \pm 2.0$ & $<0.001$ \\
LV posterior wall (mm) & $13.9 \pm 1.9$ & $10.4 \pm 1.7$ & $<0.001$ \\
LV ejection fraction $(\%)$ & $60.9 \pm 11.8$ & $65.2 \pm 3.9$ & 0.10 \\
E/A & $1.86 \pm 1.17$ & $1.31 \pm 0.42$ & 0.07 \\
E/E' & $10.1 \pm 3.2$ & $5.2 \pm 2.7$ & 0.05 \\
\hline
\end{tabular}

Table 14. Comparison of three-dimensional speckle-tracking echocardiography-derived mitral annular morphological and functional parameters between patients with cardiac amyloidosis and controls 


\begin{tabular}{|c|c|c|c|}
\hline & $\begin{array}{c}\text { CA } \\
\text { patients } \\
(n=17)\end{array}$ & $\begin{array}{c}\text { Controls } \\
(n=26)\end{array}$ & $\begin{array}{c}\mathbf{p} \\
\text { value }\end{array}$ \\
\hline \multicolumn{4}{|l|}{ Morphological parameters } \\
\hline End-diastolic MA diameter (MAD-D) (cm) & $3.09 \pm 0.56$ & $2.70 \pm 0.37$ & 0.01 \\
\hline End-diastolic MA area (MAA-D) $\left(\mathrm{cm}^{2}\right)$ & $11.22 \pm 3.56$ & $8.60 \pm 1.92$ & 0.004 \\
\hline End-diastolic MA perimeter (MAP-D) $(\mathrm{cm})$ & $12.25 \pm 1.75$ & $10.84 \pm 1.18$ & 0.003 \\
\hline End-systolic MA diameter (MAD-S) (cm) & $2.71 \pm 0.68$ & $1.87 \pm 0.31$ & $<0.001$ \\
\hline End-systolic MA area (MAA-S) $\left(\mathrm{cm}^{2}\right)$ & $8.57 \pm 3.35$ & $4.55 \pm 1.05$ & $<0.001$ \\
\hline End-systolic MA perimeter (MAP-S) (cm) & $10.84 \pm 1.89$ & $8.07 \pm 0.89$ & $<0.001$ \\
\hline \multicolumn{4}{|l|}{ Functional parameters } \\
\hline $\begin{array}{l}\text { Mitral annular fractional area change } \\
(\text { MAFAC })(\%)\end{array}$ & $24.10 \pm 13.97$ & $46.06 \pm 14.37$ & $<0.001$ \\
\hline Mitral annular fractional shortening (MAFS) $(\%)$ & $12.92 \pm 9.55$ & $30.98 \pm 11.65$ & $<0.001$ \\
\hline
\end{tabular}




\section{Discussion}

To sum up, amyloidosis is a rare disease, but the involvement of the heart in amyloidosis is quite frequent, especially in AL type. There is no difference in the gender or in the age of patients affected. The mortality and the prognosis of the disease rely on the heart function and the degree of the heart failure. Therefore, all patients with the diagnosis of amyloidosis should undergo cardiological, echocardiographic examination. If with the imaging methods, we are able to detect early the amyloid deposition and the adequate treatment can be started as soon as possible, the outcome might be better.

\subsection{Echocardiographic ascending aortic elastic properties in cardiac amyloidosis}

CA is caused by extracellular deposition of abnormal amyloid fibrils within the heart with infiltration occurring in all anatomical structures (26). To the best of the authors' knowledge, this is the first time to demonstrate alterations in echocardiographic aortic elastic properties in CA patients as compared to matched controls. Most of our CA cases $(n=17)$ showed AL amyloidosis, where AL fibrils are derived from monoclonal immunoglobulin light chains with typical multi-organ infiltration (27). In spite of the progress made over the past decades in therapy, AL cardiomyopathy proves to be associated with poor survival (26). There are several cardiac complications of myocardial amyloid fibril deposition emphasizing the most important ones: severe congestive heart failure, atrial fibrillation, ventricular arrhythmias, conduction abnormalities, orthostatic hypotensive episodes and autonomic dysfunction etc. (28). In 2 cases, TTR amyloidosis were found, where typical cardiac manifestations are arrhythmias, syncope or sudden cardiac death, dyspnoea and heart failure due to restrictive cardiomyopathy (21).

The main finding of the present study is that increased ASI and reduced AS and pulsatile change in aortic diameter could be demonstrated in CA patients as compared to age-, genderand risk factor-matched controls. The ratios of the most important cardiovascular risk factors (age, male gender, diabetes mellitus, hypertension and hypercholesterolaemia) were similar between the groups. Although actual BP values at echocardiographic measurements were higher in control subjects, echocardiographic aortic elastic properties proved to be significantly impaired in CA patients. Moreover, control subjects were more obese compared to CA patients in these patient subset, despite age and BMI were found to be predictors of increased aortic stiffness in a recent study (29). 
Several factors could play a role in increased aortic stiffness in CA. Regarding the literature, amyloid involvement of the aorta is exceedingly rare (30). However, theoretically together with myocardial tissue, aortic wall could be infiltrated latently by amyloid fibrils leading to endothelial dysfunction and impairment of its Windkessel function. Most CA patients had one or more classic cardiovascular risk factors (higher age, male gender, hypertension, diabetes mellitus or hypercholesterolaemia) which could also have an effect on arterial stiffness (31). Moreover, ventricular-arterial coupling and systolic and diastolic LV dysfunction should also be considered when interpreting these findings (32). CA patients had significantly higher aortic stiffness in higher NYHA functional classes suggesting an important role of aortic stiffness in the development of heart failure in these cases. The clinical importance of the present study is to highlight our attentation on increased aortic stiffness and associated reduced functional capacity in CA patients. However, further clinical studies are warranted to assess the effects of improvement of vascular elasticity in these cases. Theoretically all medical treatments should be considered in CA which are confirmed to improve vascular function and/or heart failure. CA patients were treated well with $\beta$-blockers and ACE-inhibitors, which are known to have positive effects on arterial stiffness over heart failure $(33,34)$.

The following important limitations have been arisen:

- The limited number of patients with cardiac amyloidosis is one of the most important limitations of the study. However, biopsy-proven amyloidosis with cardiac involvement is a rare disease.

- Differences could be detected between groups examined in risk factors (hypertension, hypercholesterolaemia), which could theoretically affect results

- A mixed population of CA patients were examined including both TTR and AL cases.

- The BP measured in the brachial artery may be different from the pressures in the ascending aorta, due to pulse pressure (PP) amplification towards the periphery. The PP amplification is related to BP: the higher the BP, the lower the PP amplification. Moreover, gender, age and body composition have a significant impact on PP amplification (35). However, echocardiography-derived aortic stiffness parameters correlate well with those from invasive methods (36).

- Controls have higher blood pressure (BP) values and PP as compared to CA patients suggesting more controlled blood pressure in CA patients. This result could strengthen our findings due to the fact that although BP values and PP proved to be higher in controls, aortic stiffness proved to be significantly increased in CA patients. 
- Measurement of aortic diameter data in systole and diastole were applied only in one plane. However, it should be considered that large vessels exhibit nonlinear variations of circumferential stress and tangent elastic moduli even within the normal pressure range (37). Therefore, aortic elastic properties could theoretically be dissimilar at different segments of the aorta.

\subsection{Left ventricular rotational mechanics in biopsy-proven cardiac amyloidosis as assessed by three-dimensional speckle-tracking echocardiography}

It is known that amyloid fibrils disrupt tissue architecture and the pre-fibril oligomers are directly toxic to myocardiac cells (38). Due to these facts cardiac dysfunction and heart failure are frequent findings in CA. Moreover, cardiac involvement inversely correlates with survival (39). Although LV twist is an essential part of LV function, the number of clinical studies in which LV rotational mechanics has been evaluated in CA is limited (40-43). Regarding to the available literature, basal LV rotations have been found to be $-4.0 \pm 4.4^{\circ}(40,41),-0.6 \pm 3.4^{\circ}$ (42) and $-2.9 \pm 2.5^{\circ}(43)$ in CA (our results proved to be $0.3 \pm 3.8^{\circ}$ ). The apical LV rotations were $5.0 \pm 2.4^{\circ}(40,41), 1.1 \pm 9.4^{\circ}(42), 9.3 \pm 3.0^{\circ}(43)$ and $7.0 \pm 3.3^{\circ}$ by the same authors. These results show large diversity and suggest that apical and basal LV rotations and, therefore, LV twist are severly reduced in the presence of CA. However, due to relatively large standard deviations of rrotational data of CA patients it was suggested to be managed separately in the present study. Different patterns of LV rotational mechanics including normo-, hypo- and hyperrotations of basal and apical segments in normal directions could be demonstrated in some CA patients. However, LV-RBR seemed to be a frequent phenomen in CA. This finding could be partially explained by the above mentioned effects of amyloid firbrils, by other reasons could not be excluded. 


\section{Limitation section.}

- Despite recent improvements in 3D echocardiographic analysis, one of the main limitations of the 3DSTE is the relatively low temporal and spatial resolution compared with the $2 \mathrm{D}$ techniques.

- Although 3DSTE has been validated for the evaluation of LA volumes and functional properties including strain assessments against different reference techniques (44-47), further studies are warranted to confirm its accuracy.

- Since no 2DSTE or other imaging technique was used together with 3DSTE and no clinical or prognostic correlations were performed between these methodologies, the accuracy of 3DSTE could not be established in this study.

- Diversity of HCM including genetic background, development of dynamic obstructions and arrhythmias etc. should also have an effect on the results.

- It is important to emphasize the importance of effects of age on LA parameters. In a recent study using the same methodology LA functional properties of HCM patients were compared with those of controls and more significant differences were found in volume-based functional parameters; the average age of the participants was significantly lower in this previous study. In the present study, the average age of the control group was increased compared to this recent study, and differences in TAEF and PAEF disappeared due to impaired LA functional parameters of this older control group (48). These facts could highlight our attention to the importance of age in influencing the results.

- Only visual grading of MR was used which could lead to misgrading, other parameters were not calculated in this particular study.

- Moreover, dependence on the place of measurement, even in healthy subjects, should be taken into account when interpreting results (49).

5.3. Comparing left atrial volumetric and functional characteristics between light-chain (AL) cardiac amyloidosis and hypertrophic cardiomyopathy by three-dimensional speckle-tracking echocardiography.

Several features of the three different phases of LA function were evaluated by 3DSTE during the same examination: systolic reservoir phase (by TASV, TAEF and peak strains), earlydiastolic conduit phase (by PASV and PAEF) and late-diastolic booster pump function (by 
AASV, AAEF and strains at atrial contraction). The present analysis showed different patterns of LA dysfunction: impaired systolic LA reservoir phase occurs in both diseases because reduced peak strains were found both in $\mathrm{CA}$ and $\mathrm{HCM}$, but on the other hand, impairment in LA active contraction phases occurred only in CA (reductions in AAEF and strains at atrial contraction).

Several imaging methodologies have been demonstrated to be useful for non-invasive evaluation of LA dimensions, volumes and function. 3DSTE is based on block-matching algorithm of the myocardial speckles of the endocardial border during their frame-to-frame motion $(25,50,51)$. It is a relatively new echocardiographic technique trying to incorporate all benefits of STE and 3D echocardiography including LA volumetric $(44-48,52,53)$ and strain assessments $(47,48,52-55)$.

It seems that LA functional remodelling related to AL-CA is more extensive than in HCM. This could be explained by the fact that while HCM represents a myopathic process affecting both ventricular and atrial myocardium, CA manifests ubiquitous involvement of the heart muscle $(56,57)$. Therefore, CA results in a much more diffuse involvement due to mainly interstitial nodular and branching deposition of amyloid which can produce a major impact on LV diastolic function that directly impairs LA structure and function. Moreover, haemodynamic reasons could also not be excluded. Higher grade of MR could be detected in 13-35\% of AL-CA and HCM patients which could have an effect on atrial remodelling as well.

Increased LA volumes and impaired LA myocardial deformation are well known features in HCM $(48,58)$. Moreover, increased LA volumes are predictors of adverse outcome and deteriorated LA function is presumed to be due to LV diastolic dysfunction as a result of hypertrophy and myocardial fibrosis (59). LA volumes and strains were found to be more affected in patients with obstruction (59). In a recent 3DSTE study, only TAEF showed significant difference from volume-based and strain functional properties between HCM patients with vs. without $\geq$ grade $2 \mathrm{MR}$, but no differences were found between the same parameters of HCM patients with vs. without classic risk factors (48). On the other hand, LA enlargement was found to be an independent predictor of long-term mortality enhancing risk stratification and management of patients presenting with amyloidosis (60). LA dysfunction could also be observed in AL amyloidosis patients without other echocardiographic features of cardiac involvement using conventional and strain echocardiography for measuring LA ejection force, LA strain and strain rate (61). All these results suggested increased LA volumes and 
reduced LA functional properties both in HCM and CA. In the present study, detailed analysis of LA dysfunction could be demonstrated by 3DSTE in CA an HCM patients. Different patterns of LA dysfunction could draw our attention to the fact that 3DSTE theoretically has a potential for differentiating these patient populations. However, further studies are warranted to confirm our findings in larger patient populations.

\subsection{Characterizing volumetric and functional properties of the right atrium in light chain (AL) cardiac amyloidosis by three-dimensional speckle-tracking echocardiography}

Among several types of amyloidosis, light chain (AL) amyloidosis is characterized by fibril deposits which are composed of monoclonal immunoglobulin light chains and is mainly associated with B-cell type diseases, like clonal plasma cell or other B-cell dyscrasias (62). The course of the disease can be progressive in case of cardiac involvement (63). The main cause of death in patients with AL amyloidosis is cardiac involvement leading to heart failure or arrhythmias and is considered to be an important prognostic factor. Without cardiac presentation, the survival is 4 years (64), in some cases, it is only 8 months (19).

In case of cardiac involvement, typically concentric ventricular thickening with RV involvement, biventricular function with normal or near normal ejection fraction and valvular thickening can be seen $(65,66)$. The speckled or granular myocardial appearance is characteristic for amyloid deposit, but the absence of this phenomenon is not rare (2). Disproportionate septal deposition can mimic hypertrophic cardiomyopathy with dynamic LV outflow tract obstruction. Atrial thrombus is common, especially in AL type, and sometimes it is associated with atrial fibrillation. Diastolic dysfunction is the earliest echocardiographic sign, it can often be detected before any clinical symptom $(15,67)$. The end-diastolic thickness of the IVS is $>12 \mathrm{~mm}$ in the absence of any other cause of LV hypertrophy in heart involvement (20). In CA, the thickness of the LV wall is not in correlation with the course and outcome of the disease (6). Doppler myocardial imaging measures of the RV can identify early impairment of cardiac function or stratify risk of death in patients with AL-CA (68). Impaired RV function was found to be a predictor of worse prognosis of early mortality in AL-CA (69). However, detailed analysis of AL-CA-associated RA volumetric and functional alterations was not documented.

With 2D echocardiography, the assessment of the RA is limited due to viewing dependency and geometric difficulties. Regularly, RA diameter and area are measured in 
AP4CH view (70,71). 3D echocardiography is a new clinical modality with ability to permit measuring accurate atrial phasic volume changes $(25,72,73)$. Moreover, several functional properties including stroke volumes and emptying fractions and strains at different phases of the cardiac cycle could be measured at the same time from the same 3D dataset allowing detailed analysis of the RA during 3DSTE $(25,73)$. In the present study, over increased RA volumes in all phases alterations in emptying fractions and strains characterizing systolic reservoir and late-diastolic active booster pump RA functions could be demonstrated. These findings could be explained by infiltration of the atrial wall with amyloid fibrils, impaired left and/or right heart failure, effects of cardiovascular risk factors, haemodynamic reasons, local fibrosis or oedema. In a recent study, severe LA dysfunction could be demonstrated in AL-CA, therefore the role of LA-RA interactions could also not be excluded (74). Segmental RA strain analyses showed RA regional differences suggesting different their contributions to RA (dys)function as mentioned before (non-uniformity of RA dysfunction). Further studies are warranted to confirm our findings in a larger patient population comparing results to other diseases with LV hypertrophy as well. It should also be examined whether demonstrated pattern of RA dysfunction is specific or not for AL-CA and have or not a diagnostic or prognostic value.

\subsection{Featuring the size and function of the mitral annulus in cardiac amyloidosis by three- dimensional speckle-tracking echocardiography}

Amyloidosis is a rare disorder in which misfolded proteins (amyloidogenic proteins) are deposited in different organs throughout the body (56). The heart is commonly affected by the disease, especially in amyloid light chain (AL) and transthyretin (TTR) amyloidosis. Cardiac involvement is thought to be the main factor in morbidity and mortality in CA. The misfolded amyloid proteins infiltrate the myocardium, leading to the development of swollen ventricular walls and septum, thickened valves and several conduction disorders. These changes affect the relaxation capability of the heart, resulting in impaired diastolic function and dilated atria. To the best of the authors' knowledge, this is the first study to examine MA morphological and functional aspects by 3DSTE in CA patients. Distended MA respecting cardiac cycle and diminished MA function could be detected in CA patients as compared to age- and gendermatched healthy controls. 
Morphological and functional MA parameters could be measured non-invasively by volumetric real-time 3D transthoracic echocardiography (RT3DE) (75). 3DSTE imaging is a newly developed 3D echocardiography technology based on 'block-matching' algorithm with a similar capability of 'en-face' assessment of valves and their annuli (25). 3DSTE has been found to be a reproducible method in the assessment of MAD and MAA with a good inter- and intraobserver agreement (76). 3DSTE has the advantage of being fast, easy and does not require a special skill set to measure the MA other than performing a simple transthoracic data acquisition following optimalization of settings. Even though spatial resolution might be decreased, after choosing the appropriate plane, from which to visualize the MA, it is very simple to trace the endocardial surface thus obtaining the diameter and perimeter of MA.

It is known that there is a strong interaction between LV, MA and the LA. In some special circumstances like volumetric enlargement and functional impairment of a heart chamber, MA function seems to compensate to maintain circulation. RT3DE- and 3DSTEderived MA dilation were found to be associated with different disorders including type 1 diabetes mellitus (T1DM) (76), hypertrophic (HCM) (75), dilated (DCM) (75) and noncompaction cardiomyopathies (NCCM) (77). For instance, although early impairment in atrial function could be detected in HCM and young T1DM patients, MA dilation was associated with augmented MA functional properties $(75,76)$. In contrast, not only LV and LA functions seem to be decreased in CA, but MA functional impaiment is also present, which could suggest exhausted compensating mechanisms in these cases similarly to DCM/NCCM $(75,77)$. These results could highlight our attention on the significance of the assessment MA functional properties in the differentiation of CA and HCM.

Several facts could explain our findings including direct involvement of MA fibrous ring by amyloids, although it was not confirmed directly by biopsy. CA could lead to volumetric changes, deformation deteriorations of heart chambers and diastolic dysfunction leading to morphological and functional deterioration of the MA. The effect of several cardiovascular risk factors including diabetes mellitus or hypertension and aging could also not be excluded.

\section{Conclusions (new observations)}


Cardiac amyloidosis is associated with increased aortic stiffness as compared to age-, genderand risk factor-matched controls.

Significant alterations in segmental LV rotation could be demonstrated in CA including frequent exist of LV-RBR.

Different patterns of LA functional characteristics could be demonstrated between AL-CA and HCM patients by 3DSTE. This could be explained by the different nature of the diseases: while HCM represents a myopathic process, AL-CA results in a much more diffuse and ubiquitous involvement of the myocardial tissue with amyloid deposition.

Significantly increased right atrial volumes and deterioration in right atrial functions could be demonstrated in light chain (AL) cardiac amyloidosis theoretically due to infiltration of the atrial wall with amyloid fibrils, but other causes including haemodynamic reasons cannot be excluded.

$\mathrm{CA}$ is associated with MA enlargement and functional impairment represented by MA fractional shortening and MA fractional area change as assessed by 3DSTE. 


\section{References}

1. Dubrey SW, Hawkins PN, Falk RH. Amyloid diseases of the heart: assessment, diagnosis, and referral. Heart 2011; 97: 75-84.

2. Banypersad SM, Moon JC, Whelan C, et al. Updates in Cardiac Amyloidosis: A review. J Am Heart Assoc 2012; 1: e000364.

3. Westermark P, Benson MD, Buxbaum JN, et al. A primer of amyloid nomenclature. Amyloid 2007; 14: 179-183.

4. Falk RH. Diagnosis and management of the cardiac amyloidoses. Circulation 2005; 112: 20472060 .

5. Westermark P, Benson MD, Buxbaum JN, et al. Amyloid protein fibril nomenclature. Amyloid 2002; 9: 197-200.

6. Rapezzi C, Merlini G, Quarta CC, et al. Systemic Cardiac Amyloidoses Disease Profiles and Clinical Courses of the 3 Main Types. Circulation 2009; 120: 1203-1212.

7. Chamarthi B, Dubrey SW, Cha K, et al. Features and prognosis of exertional syncope in light-chain associated AL cardiac amyloidosis. Am J Cardiol 1997; 80: 1242-1245.

8. Gutierrez PS, Fernandes F, Mady C, et al. Clinical, electrocardiographic and echocardiographic findings in significant cardiac amyloidosis detected only at necropsy: comparison with cases diagnosed in life. Arq Bras Cardiol 2008; 90: 191-196.

9. Merlini G. CyBorD: stellar response rates in AL amyloidosis. Blood 2012; 119: 4343-4345.

10. Merlini G, Lousada I, Ando Y, et al. Rationale application and clinical qualification for NTproBNP as a surrogate end point in pivotal clinical trials in patients with AL amyloidosis. Leukemia 2016; 30: 1979-1986.

11. Kumar S, Dispenzieri A, Lacy MQ, et al. Revised prognostic staging system for light chain amyloidosis incorporating cardiac biomarkers and serum free light chain measurements. J Clin Oncol 2012; 30: 989-995.

12. Grogan M, Dispenzieri A, Gertz MA. Light-chain cardiac amyloidosis: strategies to promote early diagnosis and cardiac response. Heart 2017; 103: 1065-1072.

13. Palladini G, Foli A, Milani P, et al. Best use of cardiac biomarkers in patients with AL amyloidosis and renal failure. Am J Hematol. 2012; 87: 465-471.

14. Murtagh B, Hammill SC, Gertz MA et al. Electrocardiographic findings in primary systemic amyloidosis and biopsy-proven cardiac involvement. Am J Cardiol. 2005; 95: 535-537.

15. Tsang W, Lang RM. Echocardiographic evaluation of cardiac amyloid. Curr Cardiol Rep. 2010; 12: $272-276$.

16. Bellavia D, Pellikka PA, Abraham TP, et al. Evidence of impaired left ventricular systolic function by Doppler myocardial imaging in patients with systemic amyloidosis and no evidence of cardiac 
involvement by standard two-dimensional and Doppler echocardiography. Am J Cardiol. 2008; 101: $1039-1045$.

17. Vogelsberg H, Mahrholdt H, Deluigi CC, et al. Cardiovascular magnetic resonance in clinically suspected cardiac amyloidosis: noninvasive imaging compared to endomyocardial biopsy. J Am Coll Cardiol. 2008; 51: 1022-1030.

18. Maceira AM, Joshi J, Prasad SK, et al. Cardiovascular magnetic resonance in cardiac amyloidosis. Circulation 2005; 111: 186-193.

19. Dispenzieri A, Gertz MA, Kyle RA, et al. Serum cardiac troponins and N-terminal pro-brain natriuretic peptide: a staging system for primary systemic amyloidosis. J Clin Oncol. 2004; 22: 3751-3757.

20. Gertz MA, Comenzo R, Falk RH, et al. Definition of organ involvement and treatment response in immunoglobulin light chain amyloidosis (AL): a consensus opinion from the 10th International Symposium on Amyloid and Amyloidosis, Tours, France, 18-22 April 2004. Am J Hematol 2005; 79: 319-328.

21. Rapezzi C, Merlini G, Quarta CC. Systemic cardiac amyloidoses: disease profiles and clinical courses of the 3 main types. Circulation 2009; 120: 1203-1212.

22. Lang RM, Bierig M, Devereux RB, et al. Recommendations for chamber quantification: a report from the American Society of Echocardiography's Guidelines and Standards Committee and the Chamber Quantification Writing Group, developed in conjunction with the European Association of Echocardiography, a branch of the European Society of Cardiology. J Am Soc Echocardiogr 2005;18:1440-1463.

23. Stefanadis C, Stratos C, Boudoulas H, et al. Distensibility of the ascending aorta: comparison of invasive and non-invasive techniques in healthy men and in men with coronary artery disease. Eur Heart J 1990; 11: 990-996.

24. Nemes A, Geleijnse ML, Forster T, et al. Echocardiographic evaluation and clinical implications of aortic stiffness and coronary flow reserve and their relation. Clin Cardiol 2008; 31: 304-309.

25. Nemes A, Kalapos A, Domsik P, et al. Three-dimensional speckle-tracking echocardiography - a further step in the non-invasive three-dimensional cardiac imaging. Orv Hetil 2012;153:1570-1577

26. Guan J, Mishra S, Falk RH, et al. Current perspectives on cardiac amyloidosis. Am J Physiol Heart Circ Physiol 2012; 302: H544-552.

27. Estep JD, Bhimaraj A, Cordero-Reyer AM, et al. Heart transplantation and end-stage cardiac amyloidosis: a review and approach to evaluation and management. Methodist Debakey Cardiovasc J 2012; 8: 8-16.

28. Mohty D, Damy T, Cosnay P, et al. Cardiac Amyloidosis: updates in diagnosis and management. Arch Cardivasc Dis 2013; 106: 528-540.

29. Nemes A, Gavallér H, Csajbók É, et al. Obesity is associated with aortic enlargement and increased stiffness: an echocardiographic study. Int J Cardiovasc Imaging 2008; 24: 165-171. 
30. Gašparović H, Petričević M, Đurić E, et al. Amyloidosis of the aortic root in a patient with polyarteritis nodosa. Coll Antropol 2014; 38: 1051-1053.

31. Breithaupt-Grögler K, Belz GG. Epidemiology of the arterial stiffness. Pathol Biol (Paris) 1999; 47: 604-613.

32. Saba PS, Cameli M, Casalnuovo G, et al; Gruppo di Studio Ipertensione, Prevenzione e Riabilitazione, Società Italiana di Cardiologia. Ventricular-vascular coupling in hypertension: methodological considerations and clinical implications. J Cardiovasc Med (Hagerstown) 2014; 15: 773-787.

33. Niu W, Qi Y. A meta-analysis of randomized controlled trials assessing the impact of beta-blockers on arterial stiffness, peripheral blood pressure and heart rate. Int J Cardiol 2016; 218: 109-117.

34. Janić M, Lunder M, Sabovič M. Arterial stiffness and cardiovascular therapy. Biomed Res Int 2014; 2014: 621437.

35. Pichler G, Martinez F, Vicente A, et al. Pulse pressure amplification and its determinants. Blood Press. 2016; 25: 21-27.

36. Stefanadis C, Stratos C, Boudoulas H, et al. Distensibility of the ascending aorta: comparison of invasive and non-invasive techniques in healthy men and in men with coronary artery disease. Eur Heart J 1990; 11: 990-996.

37. Kamenskiy AV, Dzenis YA, MacTaggart JN, et al. Nonlinear mechanical behavior of the human common, external, and internal carotid arteries in vivo. J Surg Res. 2012; 176: 329-336.

38. Kastritis E, Dimopoulos MA. Recent advances in the management of AL Amyloidosis. Br J Haematol (in press)

39. Javorniczky NR, Bodo I, Masszi T, et al. Prognostic features in light-chain amyloidosis. Orv Hetil. 2015; 156: 1577-1584.

40. Porciani MC, Cappelli F, Perfetto F, et al. Rotational mechanics of the left ventricle in AL amyloidosis. Echocardiography 2010; 27: 1061-1068.

41. Cappelli F, Porciani MC, Bergesio F, et al. Characteristics of elft ventricular rotational mechanics in patients with systemic amyloidosis, systemic hypertension and noraml left ventricular mass. Clin Physiol Funct Imaging 2011; 31: 59-65.

42. Baccouche H, Maunz M, Beck T, et al. Differentiating cardiac amyloidosis and hypertrophic cardiomyopathy by use of three-dimensional speckle tracking echocardiography. Echocardiography 2012; 29: 668-677.

43. Nucifora G, Muser D, Morocutti G, et al. Disease-specific differences of left ventricular rotational mechanics between cardiac amyloidosis and hypertrophic cardiomyopathy. Am J Physiol Heart Circ Physiol. 2014; 307: H680-688.

44. Kleijn SA, Aly MF, Terwee CB, et al. Comparison between direct volumetric and speckle tracking methodologies for left ventricular and left atrial chamber quantification by three-dimensional echocardiography. Am J Cardiol 2011; 108: 1038-1044. 
45. Nagaya M, Kawasaki M, Tanaka R, et al. Quantitative validation of left atrial structure and function by two-dimensional and three-dimensional speckle tracking echocardiography: A comparative study with three-dimensional computed tomography. J Cardiol 2013; 62: 188-194.

46. Nemes A, Domsik P, Kalapos A, et al. Comparison of three-dimensional speckle-tracking echocardiography and two-dimensional echocardiography for evaluation of left atrial size and function in healthy volunteers (Results from the MAGYAR-Healthy Study). Echocardiography 2014; 31: 865-871.

47. Nemes A, Piros GA, Lengyel C, et al. Complex evaluation of left atrial dysfunction in patients with type 1 diabetes mellitus by three-dimensional speckle tracking echocardiography - Results from the MAGYAR-Path Study. Anatol J Cardiol 2016; 16: 587-593.

48. Domsik P, Kalapos A, Chadaide S, et al. Three-Dimensional Speckle Tracking Echocardiography Allows Detailed Evaluation of Left Atrial Function in Hypertrophic Cardiomyopathy-Insights from the MAGYAR-Path Study. Echocardiography 2014; 31: 1245-1252.

49. Xia J, Gao Y, Wang Q, et al. Left atrial function examination of healthy individuals with 3D speckletracking imaging. Exp Ther Med 2013; 5: 243-246.

50. Ammar KA, Paterick TE, Khandheria BK, et al. Myocardial mechanics: understanding and applying three-dimensional speckle tracking echocardiography in clinical practice. Echocardiography 2012; 29: 861-872.

51. Urbano-Moral JA, Patel AR, Maron MS, et al. Three-dimensional speckle-tracking echocardiography: Methodological aspects and clinical potential. Echocardiography 2012; 29: $997-$ 1010.

52. Nemes A, Piros GA, Domsik P, et al. Left atrial volumetric and strain analysis by three-dimensional speckle tracking echocardiography in noncompaction cardiomyopathy - Results from the MAGYAR-Path Study. Hellenic J Cardiol 2016; 57: 23-29.

53. Piros GÁ, Domsik P, Kalapos A, et al. Left atrial ejection force correlates with left atrial strain and volume-based functional properties as assessed by three-dimensional speckle tracking echocardiography (MAGYAR-Healthy Study). Rev Port Cardiol 2016; 35: 83-91.

54. Mochizuki A, Yuda S, Oi Y, et al. Assessment of Left Atrial Deformation and Synchrony by ThreeDimensional Speckle-Tracking Echocardiography: Comparative Studies in Healthy Subjects and Patients with Atrial Fibrillation. J Am Soc Echocardiogr 2013; 26: 165-174.

55. Chadaide S, Domsik P, Kalapos A, et al. Three-Dimensional Speckle Tracking EchocardiographyDerived Left Atrial Strain Parameters Are Reduced in Patients with Atrial Fibrillation (Results from the MAGYAR-Path Study). Echocardiography 2013; 30: 1078-1083.

56. Chew C, Ziady GM, Raphael MJ, et al. The functional defect in amyloid heart disease. The "stiff heart" syndrome. Am J Cardiol 1975; 36: 438-44. 
57. Kobayashi T, Popovic Z, Bhonsale A, et al. Association between septal strain rate and histopathology in symptomatic hypertrophic cardiomyopathy patients undergoing septal myectomy. Am Heart J 2013; 166: 503-511.

58. Gabrielli L, Enriquez A, Córdova S, et al. Assessment of left atrial function in hypertrophic cardiomyopathy and athlete's heart: a left atrial myocardial deformation study. Echocardiography 2012; 29: 943-949.

59. Williams LK, Chan RH, Carasso S, et al. Effect of left ventricular outflow tract obstruction on left atrial mechanics in hypertrophic cardiomyopathy. Biomed Res Int 2015; 2015: 481245.

60. Mohty D, Pibarot P, Dumesnil JG, et al. Left atrial size is an independent predictor of overall survival in patients with primary systemic amyloidosis. Arch Cardiovasc Dis 2011; 104: 611-618.

61. Modesto KM, Dispenzieri A, Cauduro SA, et al. Left atrial myopathy in cardiac amyloidosis: implications of novel echocardiographic techniques. Eur Heart J 2005; 26: 173-179.

62. Urbano-Moral JA, Gangadharamurthy D, Comenzo RL, et al. Three-dimensional Speckle Tracking Echocardiography in Light Chain Cardiac Amyloidosis: Examination of Left and Right Ventricular Myocardial Mechanics Parameters. Rev Esp Cardiol 2015; 68: 657-664.

63. Kyle RA, Gertz MA. Primary systemic amyloidosis: clinical and laboratory features in 474 cases. Semin Hematol 1995; 32: 45-59.

64. Merlini G, Stone MJ. Dangerous small B-cell clones. Blood 2006; 108: 2520-2530.

65. Patel AR, Dubrey SW, Mendes LA, et al. Right ventricular dilation in primary amyloidosis: an independent predictor of survival. Am J Cardiol 1997; 80: 486-492.

66. Porciani MC, Lilli A, Perfetto F, et al. Tissue Doppler and strain imaging: a new tool for early detection of cardiac amyloidosis. Amyloid 2009; 16: 63-70.

67. Bellavia D, Pellikka PA, Abraham TP, et al. Evidence of impaired left ventricular systolic function by Doppler myocardial imaging in patients with systemic amyloidosis and no evidence of cardiac involvement by standard two-dimensional and Doppler echocardiography. Am J Cardiol 2008; 101: 1039-1045.

68. Bellavia D, Pellikka PA, Dispenzieri A, et al. Comparison of right ventricular longitudinal strain imaging, tricuspid annular plane systolic excursion, and cardiac biomarkers for early diagnosis of cardiac involvement and risk stratification in primary systematic (AL) amyloidosis: a 5-year cohort study. Eur Heart J Cardiovasc Imaging. 2012; 13: 680-689.

69. Szczygieł JA, Wieczorek PZ, Drozd-Sokołowska J, Michałek Pet al. Impaired right ventricular function as a predictor of early mortality in patients with light- chain cardiac amyloidosis assessed in a cardiology department. Pol Arch Intern Med. 2017; 127: 854-864.

70. Lang RM, Bierig M, Devereux RB, et al. American Society of Echocardiography"s Nomenclature and Standards Committee; Task Force on Chamber Quantification; American College of Cardiology Echocardiography Committee; American Heart Association; European Association of 
Echocardiography, European Society of Cardiology. Recommendations for chamber quantification. Eur J Echocardiogr 2006; 7: 79-108.

71. Rudski LG, Lai WW, Afilalo J, et al. Guidelines for the echocardiographic assessment of the rigth heart in adults: a report from the American Society of Echocardiography. J Am Soc Echocardiogr 2010; 23: 685-713.

72. Peluso D, Badano LP, Muraru D, et al. Right atrial size and function assessed with threedimensional and speckle-tracking echocardiography in 200 healthy volunteers. Eur Heart J Cardiovasc Imaging 2013; 14: 1106-1114.

73. Nemes A, Havasi K, Domsik P, et al. Evaluation of right atrial dysfunction in patients with corrected tetralogy of Fallot using 3D speckle-tracking echocardiography. Insights from the CSONGRAD Registry and MAGYAR-Path Study. Herz 2015; 40: 980-988.

74. Földeák D, Kormányos Á, Domsik P, et al. Left atrial dysfunction in light-chain cardiac amyloidosis and hypertrophic cardiomyopathy - A comparative three-dimensional speckletracking echocardiographic analysis from the MAGYAR-Path Study. Rev Port Cardiol. 2017; 36: 905-913.

75. Anwar AM, Soliman OI, Nemes A, et al. Assessment of mitral annulus size and function by realtime 3-dimensional echocardiography in cardiomyopathy: comparison with magnetic resonance imaging. J Am Soc Echocardiogr 2007; 20: 941-948.

76. Földeák D, Kormányos Á, Domsik $\mathrm{P}$, et al. Left atrial dysfunction in light-chain cardiac amyloidosis and hypertrophic cardiomyopathy - A comparative three-dimensional speckletracking echocardiographic analysis from the MAGYAR-Path Study. Rev Port Cardiol. 2017; 36: 905-913.

77. Nemes A, Piros GÁ, Domsik P, et al. Changes in mitral annular morphology and function in young patients with type 1 diabetes mellitus-results from the three-dimensional speckle tracking echocardiographic MAGYAR-Path Study. Quant Imaging Med Surg 2015; 5: 815-821.

78. Nemes A, Anwar AM, Caliskan K, et al. Non-compaction cardiomyopathy is associated with mitral annulus enlargement and functional impairment: a real-time three-dimensional echocardiographic study. J Heart Valve Dis 2008; 17: 31-35.

\section{Acknowledgements}


The studies reported in this work were performed at the 2nd Department of Medicine and Cardiology Center, Medical Faculty, Albert Szent-Györgyi Clinical Center, University of Szeged, Hungary.

First of all, I express my heartfelt gratitude to Prof. Dr. Attila Nemes for his continuous support during my work, who was my tutor and scientific adviser. Without his support and encouragement, this thesis would have not been performed.

I wish to express my deep gratitude to my mentor, Prof. Dr. Borbényi Zita, the head of the Hematology, who supported me in my work work and with her advices, she improved the quality of my work.

I would like to thank very much also Prof. Dr. Tamás Forster, the head of the 2nd Department of Medicine and Cardiology Center, who supported me in my work.

I would like to thank all co-authors, especially to my friends, Dr. Péter Domsik, Dr. Anita Kalapos and Dr. Mária Kohári.

I thank all my colleagues as well as nurses, assistants and all the members of the Institute.

I am deeply indebted to my family for all the love and continous support they are giving me every day and for the fact that they never stop believing in me. 
Photocopies of essential publications 